\title{
Euglenophyceae de águas continentais do Estado de São Paulo: gênero Lepocinclis Perty emend. Marin \& Melkonian in Marin et al.
}

\author{
Gabrielle Joanne Medeiros Araujo ${ }^{1,2}$ e Carlos Eduardo de Mattos Bicudo ${ }^{1}$
}

Recebido: 12.7.2016; aceito: 28.04.2017

\begin{abstract}
Euglenophyceae of continental waters of the State of São Paulo: genus Lepocinclis Perty emend. Marin \& Melkonian in Marin et al.). The floristic survey of the genus Lepocinclis was carried out through the analysis of 107 sample units and consulting the literature of the state of São Paulo. Twenty taxa were identified at species and/or infraspecific level and six of these had their names updated. The knowledge of the geographical distribution of the genus in the state was expanded more than eight times. L. acus (O.F. Müller) Marin \& Melkonian in Marin et al. var. longissima (Deflandre) D.A. Kapustin was registered for the first time in the state of São Paulo and L. fusiformis (Carter) Lemmermann var. amphirhynchus Nygaard in the southeastern Brazil. Due to the marked phenotypic plasticity, it is recommended that the identification be performed at the population level.
\end{abstract}

Keywords: nomenclatural changes, Phacaceae, southeastern Brazil, taxonomy

RESUMO - (Euglenophyceae de águas continentais do Estado de São Paulo: gênero Lepocinclis Perty emend. Marin \& Melkonian in Marin et al.). Realizou-se o levantamento florístico do gênero Lepocinclis através da análise de 107 unidades amostrais e consulta a literatura especializada do Estado de São Paulo. Foram identificados 20 táxons específicos e infraespecíficos. Seis destes tiveram sua nomenclatura atualizada. O conhecimento da distribuição geográfica do gênero no Estado foi ampliado em mais de oito vezes. L. acus (O.F. Müller) Marin \& Melkonian in Marin et al. var. longissima (Deflandre) D.A. Kapustin constituiu primeira citação de ocorrência no Estado de São Paulo e L. fusiformis (Carter) Lemmermann var. amphirhynchus Nygaard na região Sudeste do Brasil. Dada a acentuada plasticidade fenotípica observada, recomenda-se que a identificação sempre seja efetuada em nível populacional.

Palavras-chave: mudanças nomenclaturais, Phacaceae, Sudeste do Brasil, taxonomia

\section{Introdução}

A classe Euglenophyceae é constituída por microalgas flageladas, pigmentadas ou incolores e unicelulares, exceto o gênero Colacium Ehrenberg que é colonial (Alves-da-Silva et al. 2016). Os representantes deste grupo apresentam ampla distribuição em todo o mundo, notadamente em ecossistemas aquáticos continentais (Alves-da-Silva \& Bridi 2004). Entretanto, a despeito da ocorrência comum, sua taxonomia ainda permanece sujeita a bastante discussão (Alves-da-Silva \& Bicudo 2009).

Os estudos morfológicos e o reconhecimento de que plastídios podem ser adquiridos através de endosimbiose secundária revolucionaram o entendimento sobre as afinidades filogenéticas dos euglenoides e levantaram questões interessantes sobre a história evolutiva do grupo (Triemer \& Farmer 2007). O uso de informação molecular gerada, sobretudo, de pequenas subunidades de rDNA nuclear e o uso de métodos filogenéticos modernos (máxima verossemelhança e análise Bayesiana) marcaram o início de uma nova era na sistemática das Euglenophyceae, denominada "era da sistemática molecular dos euglenoides" (Linton et al. 2010). Como resultado, os euglenoides têm passado nas últimas décadas por intensas transformações em sua taxonomia e sistemática (Alves-da-Silva et al. 2013).

Os resultados obtidos nos primeiros trabalhos sobre a biologia molecular puderam confirmar que os euglenoides constituem um clado monofilético (Linton et al. 1999, 2000, Preisfeld et al. 2000, 2001, Leander et al. 2001, Busse \& Preisfeld 2002, 2003, Busse et al. 2003). No entanto, eles também apontaram para o

1. Instituto de Botânica de São Paulo, Núcleo de Pesquisa em Ecologia, Caixa Postal 68041, 04045-972 São Paulo, SP, Brasil

2. Autor para correspondência: gabijoanne@yahoo.com.br 
fato de que alguns gêneros da linhagem fotossintética estavam incorretamente agrupados (Brosnan et al. 2003), especialmente Euglena Ehrenberg, Lepocinclis Perty e Phacus Dujardin (Linton et al. 1999, 2000, Leander \& Farmer 2001, Milanowski et al. 2001, Mülner et al. 2001, Nudelman et al. 2003).

Entre estes, o gênero Lepocinclis foi estudado, visto que várias espécies originalmente descritas em outros gêneros tem sido realocadas para o mesmo, como por exemplo: (1) espécies de Euglena do subgênero Rigidae 'sensu' Pringsheim 1956 (Marin et al. 2003); (2) Phacus helicoideus Bernard e Phacus horridus Pochmann (Bennett \& Triemer 2012); e (3) todas as espécies do gênero incolor Cyclidiopsis Koršikov (Bennett \& Triemer 2014).

Marin et al. (2003) fizeram uma emenda do ponto de vista taxonômico a descrição original de Lepocinclis Perty, de modo a incluir as características morfológicas dos táxons que foram recentemente transferidos para este gênero. Atualmente, Lepocinclis Perty emend. Marin \& Melkonian in Marin et al. é constituído principalmente por espécies pigmentadas, mas também apresenta algumas incolores. Os indivíduos possuem um flagelo emergente e são rígidos ou levemente flexíveis e torcidos. Em vista taxonômica, a célula é ovada com um processo caudal curto ou é fusiforme a linear (em forma de agulha) com um processo caudal hialino conspícuo. Em vista apical, são circulares, ligeiramente comprimidas ou triangulares. A película é totalmente rígida ou quase, com estrias helicoidais ou com orientação mais ou menos longitudinal, especialmente nas células alongadas. Os cloroplastídios são numerosos, discoides, têm tamanhos similares e são desprovidos de pirenoide. Os grãos de paramido são dimórficos, os maiores frequentemente bastoniformes (especialmente nas células alongadas), discoides ou em forma de anel (Marin et al. 2003). Outros grãos de paramido menores encontram-se dispersos pelo citoplasma.

Este trabalho faz parte do Programa BIOTA/ FAPESP e, mais especificamente, do Projeto Temático "Flora Ficológica do Estado de São Paulo" e teve por objetivo providenciar o levantamento taxonômico das Euglenophyceae pigmentadas e incolores que ocorrem em águas continentais do Estado. Tanto dos materiais presentes em unidades amostrais tombadas no Herbário Científico "Maria Eneyda P. Kauffmann Fidalgo" (SP) como dos materiais observados em trabalhos publicados previamente que incluam a possibilidade de reidentificação. Atualmente, o conhecimento do gênero Lepocinclis Perty emend. Marin \& Melkonian in Marin et al. no Estado de São Paulo abrange apenas 12 táxons específicos ou infraespecíficos. No entanto, nas últimas décadas outros seis táxons descritos a partir de materiais do Estado foram formalmente transferidos para este gênero.

Devido a alta riqueza taxonômica do grupo encontrada nos materiais, os resultados serão subdivididos em algumas publicações. O presente artigo tem os seguintes objetivos: (1) identificar, descrever e ilustrar os materiais do gênero Lepocinclis Perty emend. Marin \& Melkonian in Marin et al.; (2) incluir as mudanças de nomenclatura propostas nas últimas décadas a partir de estudos filogenéticos na taxonomia clássica das Euglenophyceae do Estado; e (3) ampliar o conhecimento da distribuição geográfica do gênero no Estado de São Paulo e na região Sudeste do Brasil.

\section{Material e métodos}

O estudo abrange amostras coletadas de diversos ecossistemas aquáticos do Estado de São Paulo, cuja área é de $248.808,8 \mathrm{~km}^{2}$, inclui 645 municípios e uma população de mais de 44 milhões de habitantes. No mesmo, foi iniciado em 1960 um programa de coleta de material de algas que almejou abranger a área total do Estado, além de ambientes lênticos, semilênticos e lóticos e hábitats planctônico, perifítico, bentônico, subaéreo e metafítico.

Com o intuito de contemplar o maior número possível de municípios das 15 mesorregiões do Estado, foram analisadas unidades amostrais fixadas provenientes desse programa que se encontram tombadas no Herbário Científico do Estado "Maria Eneyda P. Kauffmann Fidalgo" (SP). As amostras foram obtidas, na maioria das vezes, próximo à margem (região litorânea do ecossistema), colocadas em frascos de vidro e fixadas, ainda em campo, com solução de Transeau na proporção de 1:1 com a água da amostra, conforme Bicudo \& Bicudo (1970), ou com solução aquosa de formalina a 3-5\%, conforme Bicudo \& Menezes (2006). Deste modo, foram analisadas 107 unidades amostrais originárias de 106 municípios do Estado de São Paulo.

Visto que não foi possível trabalhar com amostras vivas devido a inviabilidade de realização de novas coletas que abrangessem um número significativo de municípios distribuídos por todo o Estado. Foram preferencialmente selecionadas unidades amostrais mais recentemente coletadas, no intuito de minimizar 
as dificuldades de identificação decorrentes do estado de degradação do material. Salvo os municípios que apresentaram apenas materiais coletados há um período maior de tempo. No entanto, estas dificuldades puderam ser contornadas pela análise populacional dos táxons e foram pouco expressivas para o gênero, considerando o fato de que a taxonomia de Lepocinclis Perty emend. Marin \& Melkonian in Marin et al. é fortemente baseada na morfologia da célula e o referido gênero apresenta na maioria dos casos células com a película completamente rígida, ou no máximo semirígida.

O material constante na literatura especializada do Estado de São Paulo, como artigos, teses e dissertações, também foi avaliado. Contudo, foram presentemente considerados apenas os materiais que apresentaram possibilidade de reidentificação. De acordo com este critério, foram avaliadas as identificações que tinham descrição (pelo menos de suas características diagnósticas), medidas e ilustração. Os táxons observados apenas na literatura tiveram seus nomes citados na chave de identificação e no texto precedidos por um asterisco. Nos comentários de cada um destes táxons são mencionados os trabalhos em que foram apresentadas as descrições e ilustrações.

As unidades amostrais foram estudadas ao microscópio óptico binocular de marca Carl Zeiss, modelo Axioskop 2, equipado com sistemas de lentes para contraste-de-fase, câmara-clara, máquina fotográfica digital e ocular micrometrada. O material foi observado entre lâmina e lamínula, a partir das unidades amostrais concentradas.

A identificação taxonômica foi providenciada em nível de espécie e infraespecífico a partir do maior número possível de indivíduos. As identificações foram baseadas na bibliografia especializada em Euglenophyceae utilizando obras clássicas (Conrad 1934, 1935, Huber-Pestalozzi 1955, Németh 1980, Tell \& Conforti 1986), trabalhos recentes dos tipos flora (Menezes 1989, Menezes \& Fernandes 1989 , Xavier 1988, 1989, Alves-da-Silva \& Torres 1992, Conforti 1994, Xavier 1994, Alves-da-Silva \& Hahn 2004, Alves-da-Silva \& Fortuna 2006, Alves-da-Silva et al. 2011) e revisões baseadas em dados moleculares (Marin et al. 2003, Kosmala et al. 2005, Kim et al. 2010, Bennett \& Triemer 2012, 2014).
O sistema de classificação adotado é o de Bourrelly (1970) por incluir quase todos os gêneros conhecidos até o presente e classificá-los segundo critérios uniformemente aplicáveis à gama de gêneros nele contidos (Bicudo 2010). Foram incluídas, entretanto, as adaptações demandadas pelos trabalhos de biologia molecular, como a adição da família Phacaceae.

Medidas do comprimento e da largura total das células foram obtidas e a relação comprimento:largura (Rc/l) foi determinada para todos os táxons. Medidas adicionais de estruturas internas (cloroplastídios, grãos de paramido e núcleo) e externas (processo caudal) também foram verificadas dependendo de sua presença ou ausência nos espécimes.

A descrição dos táxons foi elaborada da forma mais completa e padronizada possível, de modo a incluir todas as características diacríticas, métricas e merísticas de sua fase vegetativa. Também foram incluídos comentários, relação do material examinado (unidades amostrais e/ou material da literatura do Estado) e distribuição geográfica por região e Estado no Brasil. Para determinação da distribuição geográfica foi consultada a Lista de Espécies da Flora do Brasil (Alves-da-Silva e Menezes 2015).

Ilustrações originais dos táxons foram providenciadas sob a forma de esboços a lápis. As mais representativas foram distribuídas em pranchas e arte-finalizadas à nanquim. Ilustrações de material da literatura que não foram observadas nas unidades amostrais foram reproduzidas a partir do trabalho original de sua citação e devidamente especificadas quanto à sua autoria.

\section{Resultados e Discussão}

O levantamento florístico resultou na identificação de 20 táxons em nível específico e/ou infraespecífico, dos quais dois constituem primeira citação de ocorrência para o Estado de São Paulo e um para a região Sudeste do Brasil.

Classe Euglenophyceae

Ordem Euglenales

Família Phacaceae Kim et al. 2010

Gênero Lepocinclis Perty 1852 emend. Marin \& Melkonian in Marin et al. 2003.

Chave para reconhecer as espécies e variedades taxonômicas identificadas neste trabalho

1. Célula muito alongada, no mímino 4 vezes mais longa que larga

2. Grãos de paramido numerosos, bastoniformes

3. Cloroplastídios ausentes L. cyclidiopsis

3. Cloroplastídios presentes 
4. Célula 80,0-175,0 × 5,0-14,0 $\mu \mathrm{m}(\mathrm{Rc} / 1=7,8-20,0)$ L. acus var. acus

4. Célula 210,0-252,0 × 8,0-12,0 $\mu \mathrm{m}(\mathrm{Rc} / 1=20,7-27,6)$ L. acus var. longissima

2. Grãos de paramido principais 2, elípticos ou bastoniformes com ou sem perfuração central

5. Película com ornamentação

6. Papilas piramidais ou piramidal truncadas L. fusca

6. Papilas \pm cúbicas L. spirogyroides

5. Película sem ornamentação

7. Corte óptico transversal elíptico L. oxyuris

7. Corte óptico transversal triangular * L. tripteris

1. Célula globosa a pouco alongada, no máximo 3 vezes mais longa que larga

8. Grãos de paramido principais geralmente 2, grandes, anelares

9. Película com estrias longitudinais

L. steinii var. steinii

9. Película com estrias espiraladas

10. Estrias dextrógiras * L. pyriformis

10. Estrias levógiras

11. Polo posterior progressivamente atenuado em processo caudal pouco delimitado do resto da célula 12. Polo anterior com mamilo proeminente L. fusiformis var. amphirhynchus

12. Polo anterior com mamilo pouco desenvolvido L. fusiformis var. fusiformis

11. Polo posterior abruptamente terminando em processo caudal bem definido

13. Processo caudal cônico

14. Película com espessamento em torno da base do processo caudal

* L. cylindrica var. cylindrica

14. Película sem ou com espessamento discreto na base do processo caudal .... L. ovum var. ovum 13. Processo reduzido a mamilo

15. Polo anterior com proeminência truncada, bem desenvolvida * L. ovum var. conica

15. Polo anterior sem tal proeminência

16. Célula globosa ou subglobosa $(\mathrm{Rc} / 1=1,0-1,2)$

L. ovum var. globula

16. Célula subcilíndrica a amplamente elíptica $(\mathrm{Rc} / 1=1,3-2,5)$... L. ovum var. dimidio-minor

8. Grãos de paramido numerosos, discoides ou elípticos, nunca anelares

17. Estrias dextrógiras

18. Célula com processo caudal (ca. $8 \mu \mathrm{m}$ )

L. salina var. vallicauda

18. Célula sem processo caudal L. salina var. salina

17. Estrias levógiras

19. Célula com processo caudal L. texta var. richardiana

19. Célula sem processo caudal L. texta var. texta

Lepocinclis acus (O.F. Müller) Marin \& Melkonian in Marin et al. var. acus, Protist 154: 104. 2003 三Vibrio acus O.F. Müller, Animacula Infusoria. 59, Tab. 8, fig. 9-10. 1786.

Figuras 1-4

Célula fusiforme alongada, 80-175 $\mu \mathrm{m}$ compr., 5-14 $\mu \mathrm{m}$ larg., $\mathrm{Rc} / 1=7,8-20,0$, pigmentada; polo anterior truncado, abertura do canal subapical; polo posterior atenuado em processo caudal hialino, cônico, longo, reto ou inclinado, 9-38 $\mu \mathrm{m}$ compr.; película hialina, estrias finas, longitudinais a levemente helicoidais, às vezes ausentes ou de difícil visualização; cloroplastídios numerosos, discoides, 1-3 $\mu \mathrm{m}$ diâm.; grãos de paramido 3-18, bastoniformes, tamanho muito variável, 6-22 $\mu \mathrm{m}$ compr., 1,5-8 $\mu \mathrm{m}$ larg.; núcleo aproximadamente central, elíptico, 7-11 $\mu \mathrm{m}$ compr., 4-8 $\mu \mathrm{m}$ larg.; flagelo emergente 1, ca. 0,2 do comprimento celular; estigma não observado.

A partir da análise de dados moleculares, Marin et al. (2003) transferiram espécies de Euglena com película rígida para Lepocinclis. Entre estas está Euglena acus (O.F. Müller) Ehrenberg. De acordo com Gojdics (1953), E. acus (O.F. Müller) Ehrenberg apresenta variedades com valor sistemático duvidoso. Considerando o grande polimorfismo apresentado pela espécie, alguns autores propuseram reunir diversas dessas variedades como sinônimos da variedade típica. Van Oye (1924) e Németh (1980) propuseram que as var. minor Hansgirg e var. rigida Hübner, bem como as espécies E. acutissima 


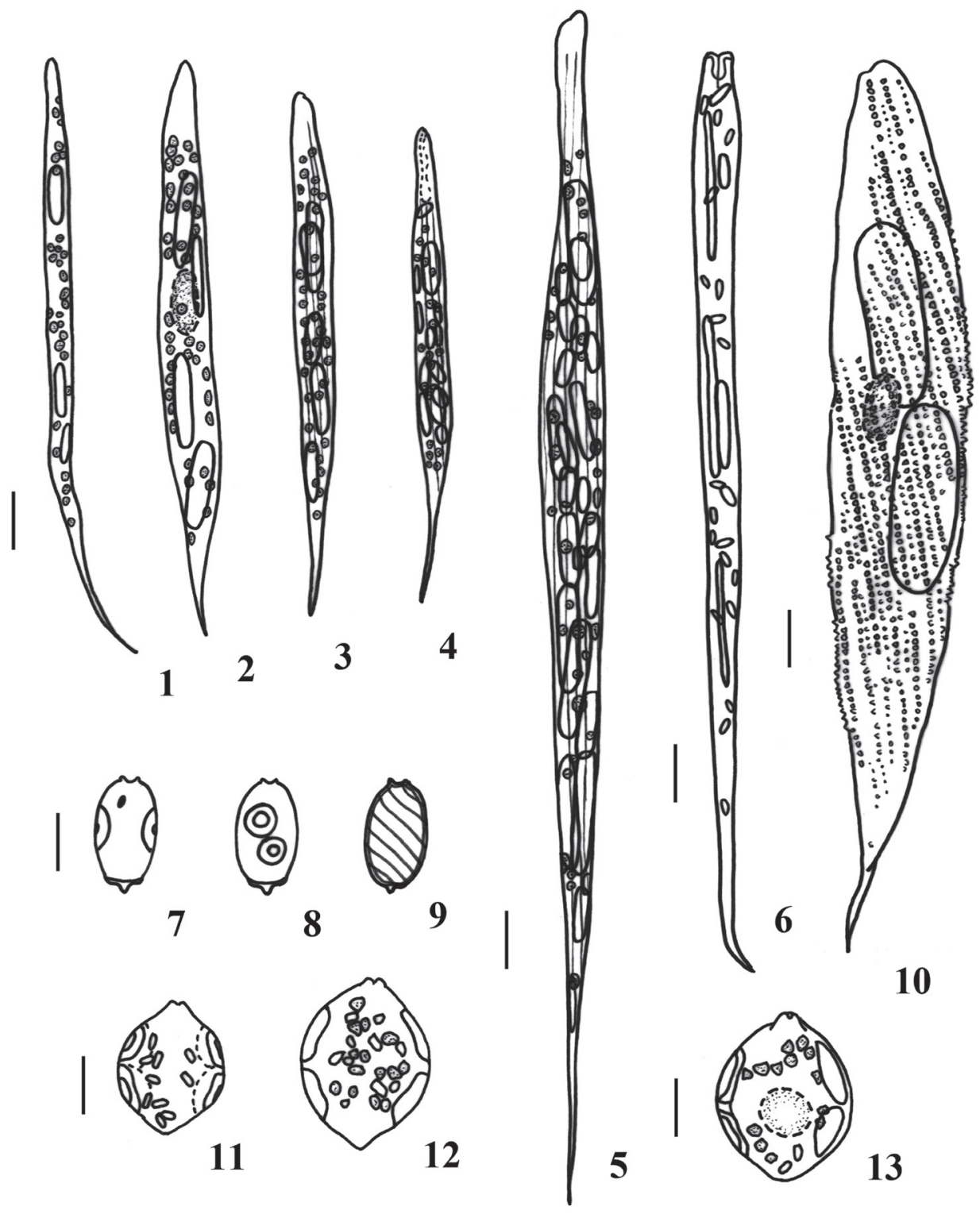

Figuras 1-13. Táxons do gênero Lepocinclis no Estado de São Paulo, SP, Brasil. 1-4. L. acus var. acus. 5. L. acus var. longissima. 6. L. cyclidiopsis. 7-9. * L. cylindrica var. cylindrica (Xavier 1989). 10. L. fusca. 11-12. L. fusiformis var. fusiformis. 13. L. fusiformis var. amphirhynchus. Escala $=10 \mu \mathrm{m}$.

Figures 1-13. Taxa of genus Lepocinclis from the State of São Paulo, SP, Brazil. 1-4. L. acus var. acus. 5. L. acus var. longissima. 6. L. cyclidiopsis. 7-9. * L. cylindrica var. cylindrica (Xavier 1989). 10. L. fusca. 11-12. L. fusiformis var. fusiformis. 13. L. fusiformis var. amphirhynchus. Scale bar $=10 \mu \mathrm{m}$.

Lemmermann e Phacus acutissima Bernard fossem consideradas sinônimos heterotípicos de Euglena acus (O.F. Müller) Ehrenberg var. acus, uma vez que deveriam constituir diferentes estádios no desenvolvimento de um mesmo indivíduo. Recentemente, Marin et al. (2003) também propuseram que E. acutissima Lemmermann e E. lata Swirenko fossem consideradas sinônimos de Lepocinclis acus (O.F. Müller) Marin \& Melkonian in Marin et al. Contudo, não fizeram qualquer sugestão com relação às variedades da espécie. Portanto, considerando que a situação das categorias infraespecíficas de $L$. acus (O.F. Müller) Marin \& Melkonian in Marin et al. ainda não foi analisada em termos moleculares e que mesmo na literatura clássica já se reconhece a acentuada plasticidade fenotípica da espécie, optamos por reunir todas as variedades descritas acima como sinônimos de L. acus (O.F. Müller) Marin \& Melkonian in Marin et al. var. acus. 
Material examinado: BRASIL. São Paulo: Guaratinguetá, BR-116, lago próximo do Clube dos 500, 1-IV-1966, C.E.M. Bicudo (SP96956); Rancharia, Vila Agissê, ribeirão Capivari, 25-VIII-1973, D.M. Vital (SP114513); Itirapina, Instituto Florestal, lagoa de estabilização, 26-I-1975, O.A. Silva (SP123858); Sumaré, Acampamento Batista, lago, 11-II-1975, L. Sormus (SP123865); Pirassununga, SP-225, km 23, bairro Cascalho, lago, ?-XII-1973, P.A.C. Senna (SP123900); Porangaba, SP-280, km 127, lago, 11-V-1977, C.R. Leite (SP139741); Andradina, estrada da Lagoinha, Estância Marrequinho, 15-I-1992, L.H.Z. Branco (SP239234); Itu, SP-312, km 112,5, Fazenda Potiguara, represa com bastante Eichhornia, Cyperus papyrus e Myriophyllum, 20-III-1990, A.A.J. Castro \& C.E.M. Bicudo (SP255725); Cerqueira César, SP-270, km 13, riacho, 21-IX-2000, L.L. Morandi \& S.P. Schetty (SP336348); Piquete, estrada LorenaPiquete, km 65, riacho, 19-IX-2001, C.E.M. Bicudo, D.L. Costa \& F.C. Pereira (SP355360); Macedônia, rodovia Alberto Faria, sentido Estrela-Macedônia, $2 \mathrm{~km}$ antes da entrada para Macedônia, açude, , 25-IV-2001, C.E.M. Bicudo, S.M.M. Faustino \& D.L. Costa (SP355366); Salesópolis, SP-88, km 99/100, dreno, 18-IX-2001, C.E.M. Bicudo, D.L. Costa \& F.C. Pereira (SP355371); Manduri, sem especificação do local, s.d., C.F. Carmo (SP371068); Parapuã, SP-425, $\mathrm{km}$ 1, charco com taboa, 15-V-2001, C.E.M. Bicudo \& D.C. Bicudo (SP371186).

Distribuição geográfica: Centro-Oeste (Goiás), Norte (Acre), Sudeste (Minas Gerais, Rio de Janeiro e São Paulo), Sul (Paraná, Rio Grande do Sul e Santa Catarina).

Lepocinclis acus (O.F. Müller) Marin \& Melkonian in Marin et al. var. longissima (Deflandre) D.A. Kapustin, Algologie 21(1): 138. 2011 三 Euglena acus Ehrenberg var. longissima Deflandre, Revue Algologique 1(3): 238, pl. 4, fig. 1-3. 1924.

\section{Figura 5}

Célula fusiforme alongada, 210-252 $\mu \mathrm{m}$ compr., 8-12 $\mu \mathrm{m}$ larg., $\mathrm{Rc} / 1=20,7-27,6$, pigmentada; polo anterior truncado, abertura do canal subapical; polo posterior atenuado em processo caudal hialino, cônico, longo, reto ou ligeiramente inclinado, 45-70 $\mu \mathrm{m}$ compr.; película hialina, estrias finas, longitudinais a levemente helicoidais, às vezes de difícil visualização; cloroplastídios numerosos, discoides, 1-3 $\mu \mathrm{m}$ diâm.; grãos de paramido 8-29, bastoniformes, tamanho muito variável, 11-25 $\mu \mathrm{m}$ compr., 1,5-5 $\mu \mathrm{m}$ larg.; núcleo, estigma e flagelo não observados.
Como mencionado anteriormente, as categorias infraespecíficas de L. acus (O.F. Müller) Marin \& Melkonian in Marin et al. ainda não foram definidas em nível molecular. Todavia, com base morfológica, Kapustin (2011) fez novas combinações para acomodar algumas variedades da espécie após a transferência de E. acus (O.F. Müller) Ehrenberg para o gênero Lepocinclis. Entre estas está a variedade longissima Deflandre, que difere da típica da espécie pelas maiores dimensões do comprimento da célula e pela maior Rc/l. A favor de considerar esta variedade independente da var. acus está a expressiva diferença no intervalo das medidas do comprimento total e a ausência de valores intermediários. Fato idêntico havia sido apontado por Menezes (1989) em amostras do Estado do Rio de Janeiro e por Alves-da-Silva \& Torres (1994) em material do Rio Grande do Sul.

Material examinado: BRASIL. São PAUlo: Araçatuba, rodovia Marechal Rondon, local não especificado, com Cyperaceae, gramíneas e Myriophyllum, 15-I-1992, L.H.Z. Branco (SP239239); General Salgado, rodovia Jesulino da Costa Frota (estrada vicinal), 1,5 km da estrada SP-310, local não especificado, com Cyperaceae, gramíneas e Typha, 5-XII-1991, L.H.Z. Branco (SP239241); Manduri, sem especificação do local, s.d., C.F. Carmo (SP371068).

Distribuição geográfica: Centro-Oeste (Mato Grosso), Norte (Acre), Sudeste (Rio de Janeiro), Sul (Paraná, Rio Grande do Sul e Santa Catarina). Primeiro registro para o Estado de São Paulo.

Lepocinclis cyclidiopsis (Koršikov) Bennett \& Triemer, Journal of Eukaryotic Microbiology 61: 168. 2014 三 Cyclidiopsis acus Koršikov, Travaux de la Station Biologique Borodinskaja 4: 225, pl. 2, fig. 2. 1917.

\section{Figura 6}

Célula aproximadamente cilíndrica, 163,2-170 $\mu \mathrm{m}$ compr., 8-9,5 $\mu \mathrm{m}$ larg., Rc/l=17,9-20,4, despigmentada; polo anterior truncado, abertura apical com reentrância nítida; polo posterior atenuado em processo caudal hialino, cônico, longo, reto ou inclinado; película hialina, estrias finas, longitudinais, difícil visualização; grãos de paramido numerosos, bastoniformes, tamanho muito variável, 15-26 $\mu \mathrm{m}$ compr., 1,5-3 $\mu \mathrm{m}$ larg., outros menores dispersos no citoplasma; núcleo e flagelo não observados.

Desde sua proposição em 1917, a validade do gênero Cyclidiopsis tem sido motivo de debate entre os taxonomistas. Recentemente, embasados em análises 
moleculares, Bennett \& Triemer (2014) transferiram as espécies deste gênero para Lepocinclis. A espécie-tipo Cyclidiopsis acus Koršikov passou a ser denominada Lepocinclis cyclidiopsis (Koršikov) Bennett \& Triemer, uma vez que o epíteto específico encontrava-se préocupado. Entre as espécies que foram consideradas sinônimos de Lepocinclis cyclidiopsis (Koršikov) Bennett \& Triemer estão três espécies descritas por Skvortzov \& Noda (1969) a partir de amostras do Estado de São Paulo (Cyclidiopsis aculeata Skvortzov \& Noda, C. brasiliana Skvortzov \& Noda e C. depressa Skvortzov \& Noda). Lepocinclis cyclidiopsis (Koršikov) Bennett \& Triemer lembra, morfologicamente, Lepocinclis acus (O.F. Müller) Marin \& Melkonian in Marin et al., do qual difere pela ausência de cloroplastídios e por apresentar a abertura apical com uma reentrância bem característica, enquanto que em L. acus (O.F. Müller) Marin \& Melkonian in Marin et al. tal abertura é subapical e menos conspícua.

Material examinado: BRASIL. S̃̃o PAULO: Rancharia, Vila Agissê, ribeirão Capivari, 25-VIII-1973, D.M. Vital (SP114513).

Distribuição geográfica: Sudeste (São Paulo), Sul (Rio Grande do Sul). Primeira vez a ser mencionada para o Brasil como Lepocinclis cyclidiopsis (Koršikov) Bennett \& Triemer.

* Lepocinclis cylindrica (Koršikov) Conrad var. cylindrica, Archiv für Protistenkunde 82(2): 212, fig. 11. 1934 三Lepocinclis ovum (Ehrenberg) Minkevich var. cylindrica Koršikov, Archives Russes de Protistologie Moscow 7: 153, 157, fig. 4-7. 1928.

Figuras 7-9

Célula aproximadamente oblonga, 22-24 $\mu \mathrm{m}$ compr., 13-15 $\mu \mathrm{m}$ larg., Rc/1 = ca. 1,6, pigmentada; polo anterior arredondado, abertura do canal apical crateriforme na base; polo posterior abruptamente terminando em processo caudal cônico, curto, espessamento da película na base; película amarelada a castanho-clara, estrias levógiras; cloroplastídios numerosos, discoides; grãos de paramido principais geralmente 2, anelares; núcleo volumoso, ligeiramente excêntrico.

A descrição original de Lepocinclis cylindrica (Koršikov) Conrad var. cylindrica está em Koršikov (1928), que o propôs na categoria variedade, como Lepocinclis ovum (Ehrenberg) Minkevich var. cylindrica Koršikov. Anos mais tarde, Conrad (1934) elevou a variedade à categoria espécie com base nas características do polo anterior, que apresenta poro flagelar crateriforme, bem como do polo posterior que possui processo caudal curto e espessamento da película na sua base. Este táxon foi descrito para o município de São Paulo por Xavier $(1989,1994)$.

Material examinado: observado apenas na literatura especializada do Estado de São Paulo.

Distribuição geográfica: Sudeste (São Paulo), Sul (Rio Grande do Sul).

Lepocinclis fusca (Klebs) Kosmala \& Zakryś in Kosmala et al., Journal of Phycology 41: 1264. $2005 \equiv$ Euglena spirogyra Ehrenberg var. fusca Klebs, Untersuchungen aus dem Botanischen Institut zu Tübingen 1(2): 307, pl. 3, fig. 13. 1883.

Figura 10

Célula cilíndrica a fusiforme alongada, 130-220 $\mu \mathrm{m}$ compr., 18-35 $\mu \mathrm{m}$ larg., Rc/l = 5,8-8,8, pigmentada, achatada dorsiventralmente, às vezes torcida; polo anterior arredondado a truncado, abertura do canal subapical; polo posterior atenuado em processo caudal cônico, longo, distintamente curvo, 10-26 $\mu \mathrm{m}$ compr.; película castanho claro a castanho escuro, estrias finas, levógiras, cobertas por fileiras de papilas piramidais ou piramidal truncadas, com tamanho e grau de desenvolvimento variáveis; cloroplastídios numerosos, discoides, ca. $4 \mu \mathrm{m}$ diâm.; grãos de paramido principais 2, elípticos ou bastoniformes com ou sem perfuração central, 1 anterior e outro posterior ao núcleo, 19-62 $\mu \mathrm{m}$ compr., 4-15 $\mu \mathrm{m}$ larg.; núcleo oblongo, grande, aproximadamente central, 14-23 $\mu \mathrm{m}$ compr., 6-13 $\mu \mathrm{m}$ larg.; estigma e flagelo não observados.

Klebs (1883) propôs Euglena spirogyra Ehrenberg var. fusca Klebs distinguindo-a da variedade-tipo da espécie pelas suas maiores dimensões celulares, coloração mais intensa da película e flagelo relativamente mais longo. Três décadas depois, com base apenas no maior tamanho do flagelo, Lemmermann (1910) elevou a var. fusca Klebs à categoria espécie, sob a combinação E. fusca (Klebs) Lemmermann. Recentemente, Marin et al. (2003) transferiram E. spirogyra Ehrenberg para o gênero Lepocinclis como L. spirogyroides Marin \& Melkonian in Marin et al. Contudo, não especificaram de qual variedade(s) era(m) as cepas avaliadas. Kosmala et al. (2005) avaliaram a posição taxonômica e filogenética de L. spirogyroides (= E. spirogyra Ehrenberg) incluindo exemplares de E. fusca (Klebs) Lemmermann e propuseram uma combinação nova, 
Lepocinclis fusca (Klebs) Kosmala \& Zakryś in Kosmala et al. Segundo os últimos autores, a forma das papilas independe da fase ontogenética e das condições ambientais constituindo, portanto, a melhor característica para distinquir L. spirogyroides Marin \& Melkonian in Marin et al. (papilas cubóides) de $L$. fusca (Klebs) Kosmala \& Zakryś in Kosmala et al. (papilas piramidais ou piramidal truncadas).

Material examinado: BRASIL. S̃̃o PAulo: Ibiúna, rodovia Cotia-Ibiúna, km 54, rio Sorocá-Mirim, 19-IX-1973, L. Sormus (SP114515); Bauru, rio Batalha, próximo da estrada Bauru-Piratininga, 21-VIII-1973, D.M. Vital (SP130790); Avaré, SP310, km 276, lago, 23-I-1976, O. Yano \& R.C.A. Souza (SP130956); Porangaba, SP-280, km 127, lago, 11-V-1977, C.R. Leite (SP139741); Andradina, estrada da Lagoinha, Estância Marrequinho, 15-I-1992, L.H.Z. Branco (SP239234); General Salgado, rodovia Jesulino da Costa Frota (estrada vicinal), 1,5 km da estrada SP-310, local não especificado, com Cyperaceae, gramíneas e Typha, 5-XII-1991, L.H.Z. Branco (SP239241); Capivari, SP-308, km 132, charco com Typha, Eichhornia e Pistia, 20-III-1990, A.A.J. Castro \& C.E.M. Bicudo (SP255723); Reginópolis, SP-331, km 115,2, à esquerda, sentido Pirajuí, lado direito do rio Batalha, $500 \mathrm{~m}$ depois da entrada de Reginópolis, brejo com macrófitas, 22-II-1992, C.E.M. Bicudo \& D.C. Bicudo (SP255770); Novo Horizonte, SP-304, km 451, charco, 14-II-2001, C.E.M. Bicudo, S.M.M. Faustino \& L.R. Godinho (SP336349); Piquete, estrada Lorena-Piquete, km 65, riacho, 19-IX-2001, C.E.M. Bicudo, D.L. Costa \& F.C. Pereira (SP355360); Turmalina, SP-462, km 14, riacho, 25-IV-2001, C.E.M. Bicudo, D.L. Costa \& S.M.M. Faustino (SP355398); Parapuã, SP-425, km 1, charco com taboa, 15-V-2001, C.E.M. Bicudo \& D.C. Bicudo (SP371186).

Distribuição geográfica: Centro-Oeste (Distrito Federal e Mato Grosso), Nordeste (Sergipe), Norte (Amazonas e Rondônia), Sudeste (Espírito Santo, Minas Gerais, Rio de Janeiro e São Paulo), Sul (Paraná, Rio Grande do Sul e Santa Catarina).

Lepocinclis fusiformis (Carter) Lemmermann var. fusiformis, Berichte der deutsche botanischen Gesellschaft 19: 89. 1901 E Euglena fusiformis Carter, Annals and Magazine of Natural History, série 2, 3 : 17, pl. 1: fig. 15, 17. 1859.

Figuras 11-12
Célula citroniforme, 25-34 $\mu \mathrm{m}$ compr., 20-25 $\mu \mathrm{m}$ larg., $\mathrm{Rc} / 1=1,2-1,4$, pigmentada; polo anterior mamilado, 1-2 $\mu \mathrm{m}$ compr., abertura do canal apical; polo posterior progressivamente atenuado em processo caudal pouco delimitado do resto da célula; película hialina, estrias levógiras muito delicadas, difícil visualização; cloroplastídios numerosos, discoides, ca. $2 \mu \mathrm{m}$ diâm.; grãos de paramido principais 2, anelares, curvados, laterais, outros menores dispersos no citoplasma, ca. $3 \mu \mathrm{m}$ compr.; núcleo, estigma e flagelo não observados.

Esta espécie é única pela célula fusiforme a citroniforme, com o polo anterior em forma de mamilo (Alves-da-Silva \& Hahn 2004). Os indivíduos ora analisados apresentaram morfologia e amplitude das dimensões celulares próximas das fornecidas por Lemmermann (1901). No entanto, no que tange a presença de estrias delicadas, os presentes espécimes divergiram do apontado pelo autor que descreveu a película significativamente estriada em hélice. A presença de estrias tênues e de difícil visualização também foi apontada por Alves-da-Silva \& Torres (1992), Alves-da-Silva \& Hahn (2004) e Alves-daSilva et al. (2011) em populações do Estado do Rio Grande do Sul.

Material examinado: BRASIL. São Paulo: Pilar do Sul, SP-250, km 127, à direita, sentido São Paulo-Pilar do Sul, bairro Turvinho, rio Turvinho, 17-IV-1989, A.A.J. Castro, C.E.M. Bicudo \& D.C. Bicudo (SP188431); Capivari, SP-308, km 132, charco com Typha, Eichhornia e Pistia, 20-III-1990, A.A.J. Castro \& C.E.M. Bicudo (SP255723).

Distribuição geográfica: Centro-Oeste (Distrito Federal e Mato Grosso), Norte (Amazonas), Sudeste (Rio de Janeiro e São Paulo), Sul (Paraná, Rio Grande do Sul e Santa Catarina).

Lepocinclis fusiformis (Carter) Lemmermann var. amphirhynchus Nygaard, Det Kongelige Danske Videnskabernes Selskab, Biologiske Skrifter 7(1): 167, fig. 101. 1949.

Figura 13

Célula citroniforme, 30-31 $\mu \mathrm{m}$ compr., 23-25 $\mu \mathrm{m}$ larg., $\mathrm{Rc} / 1=1,2-1,3$, pigmentada; polo anterior com mamilo obtuso, proeminente, ca. $4 \mu \mathrm{m}$ compr., abertura do canal apical; polo posterior progressivamente atenuado em processo caudal pouco delimitado do resto da célula; película hialina, estrias levógiras muito delicadas, difícil visualização; cloroplastídios numerosos, discoides, ca. 2,5 $\mu \mathrm{m}$ diâm.; grãos de 
paramido principais 2, anelares, curvados, laterais; núcleo globoso, ligeiramente posterior, ca. 9 um diâm.; estigma e flagelo não observados.

Difere da variedade-tipo da espécie por possuir o polo anterior mais proeminente (Alves-da-Silva \& Fortuna 2006). Assim como sucedeu com os espécimes da variedade-tipo, os atuais da var. amphirhynchus Nygaard apresentaram estrias delicadas, de difícil visualização. Fato idêntico foi observado por Alves-da-Silva et al. (2011) em exemplares da var. amphirhynchus Nygaard.

Material examinado: BRASIL. São Paulo: Pirassununga, SP-225, km 23, bairro Cascalho, lago, ?-XII-1973, P.A.C. Senna (SP123900).

Distribuição geográfica: Nordeste (Paraíba), Norte (Amazonas e Pará), Sul (Rio Grande do Sul). Primeira notícia da ocorrência da variedade no Estado de São Paulo e na Região Sudeste do Brasil.

Lepocinclis ovum (Ehrenberg) Minkevich var. ovum, Trudy Imperatorskago S.-Peterburgskago Obshchestva Estestvoispytatelei. Vypusk 29: 241. 1899 三Euglena ovum Ehrenberg, Bericht über die zur Bekanntmachung geeigneten Verhandlungen der Königlich Preussischen Akademie der Wissenschaften zu Berlin, 200. 1840.

Figuras 14-17

Célula aproximadamente fusiforme a elíptica, 25-40 $\mu \mathrm{m}$ compr., 11-21 $\mu \mathrm{m}$ larg., Rc/1 = 1,3-2,8, pigmentada; polo anterior arredondado, abertura do canal apical; polo posterior terminando em processo caudal cônico, relativamente longo, reto ou inclinado, algumas vezes com espessamento na base, 3-7 $\mu \mathrm{m}$ compr.; película hialina a castanho-amarelada, estrias grossas, levógiras, fácil visualização; cloroplastídios numerosos, discoides, 1,5-3 $\mu \mathrm{m}$ diâm.; grãos de paramido principais 1-2, anelares, curvados, laterais; núcleo aproximadamente esférico, posterior, ca. $6 \mu \mathrm{m}$ diâm.; estigma e flagelo não observados.

A grande variação morfológica e métrica nas populações desta espécie resultaram na delimitação de 38 variedades taxonômicas, as quais são distinguidas da variedade-tipo, sobretudo, pelas características do processo caudal e pelas dimensões celulares. Menezes (1994) confirmou a ampla plasticidade fenotípica da espécie e sugeriu que muitas das categorias infraspecíficas descritas poderiam representar expressões morfológicas de um único táxon. Neste sentido, podemos observar que alguns dos atuais exemplares apresentaram morfologia e dimensões comparáveis com as da var. bütschlii (Lemmermann) Conrad, inclusive no que diz respeito à posse de um espessamento na base do processo caudal. No entanto, a var. bütschlii (Lemmermann) Conrad passou a ser considerada sinônimo taxonômico da típica da espécie em um amplo estudo sobre o polimorfismo de Lepocinclis ovum (Ehrenberg) Minkevich realizado por Menezes (1987). Posição idêntica foi presentemente adotada por ocorrer em uma mesma unidade amostral indivíduos com morfologia semelhante à descrita para cada uma das variedades em pauta, ao lado de outros com características intermediárias. Considerando que a cor da película e o espessamento são dependentes da idade da célula, é provável que L. ovum (Ehrenberg) Minkevich var. bütschlii (Lemmermann) Conrad constitua um estágio no desenvolvimento de L. ovum (Ehrenberg) Minkevich var. ovum (Menezes 1994).

Material examinado: BRASIL. São PAULo: Porangaba, SP-280, km 127, lago, 11-V-1977, C.R. Leite (SP139741); Angatuba, SP-270, km 203,7, à direita, sentido Angatuba-Itapetininga, chácara Casa de Pedra, lago com Cyperaceae, 17-IV-1989, A.A.J. Castro, C.E.M. Bicudo \& D.C. Bicudo (SP188215); Assis, SP-33, km 435, lagoa com vegetação aquática, 21-VII-1991, M.C. Bittencourt-Oliveira (SP239089); Andradina, estrada da Lagoinha, Estância Marrequinho, 15-I-1992, L.H.Z. Branco (SP239234); São Pedro, SP-304, km 127, lago do Restaurante do Lago, com Nymphaea elegans e Salvinia, 20-III1990, A.A.J. Castro \& C.E.M. Bicudo (SP255724); Itu, SP-312, km 112,5, Fazenda Potiguara, represa com bastante Eichhornia, Cyperus papyrus e Myriophyllum, 20-III-1990, A.A.J. Castro \& C.E.M. Bicudo (SP255725); Itaju, SP-304, km 347,5, sentido Ibitinga, açude com plantas aquáticas, 22-II-1992, C.E.M. Bicudo \& D.C. Bicudo (SP255771); Novo Horizonte, SP-304, km 451, charco, 14-II-2001, C.E.M. Bicudo, S.M.M. Faustino \& L.R. Godinho (SP336349); Jundiaí, SP-360, km 68, riacho, 5-V-2000, C.E.M. Bicudo \& S.P. Schetty (SP365686).

Distribuição geográfica: Centro-Oeste (Goiás, Mato Grosso do Sul e Mato Grosso), Norte (Amazonas, Rondônia e Tocantins), Sudeste (Rio de Janeiro e São Paulo), Sul (Rio Grande do Sul e Santa Catarina).

* Lepocinclis ovum (Ehrenberg) Minkevich var. conica Allorge \& Lefèvre, Bulletin du Société Botanique de France 72(6): 130, fig. 73-74. 1925. Figuras 18-20 


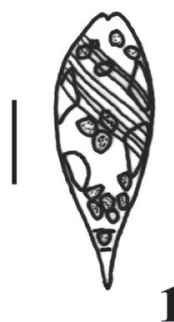

14
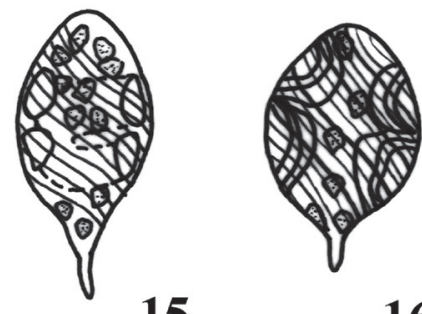

15
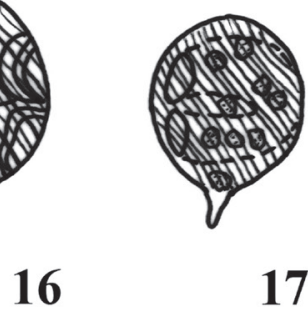

16

17
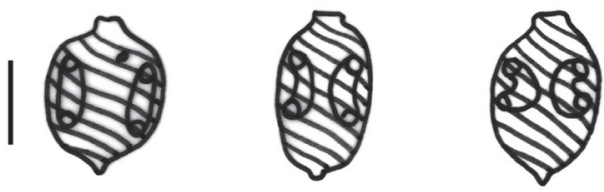

19

20
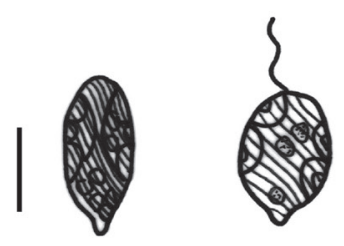

21
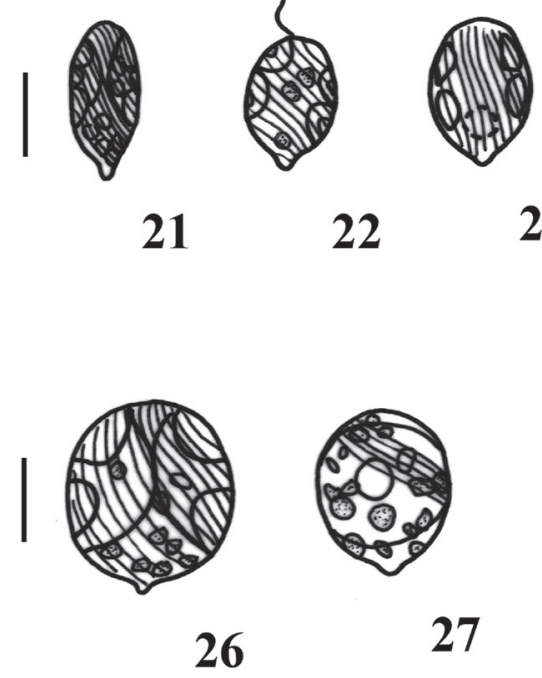

23
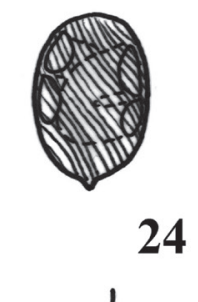

24

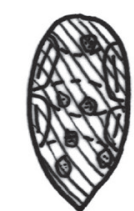

25

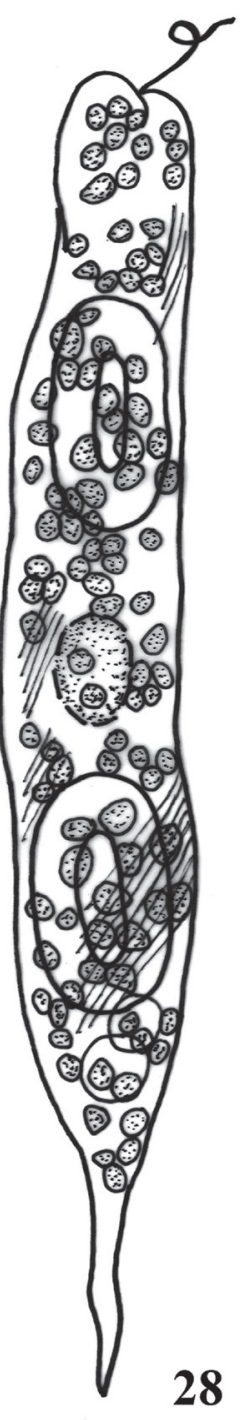

29

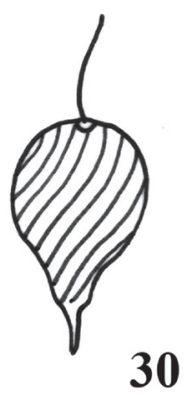

28

Figuras 14-30. Táxons do gênero Lepocinclis no Estado de São Paulo, SP, Brasil. 14-17. L. ovum var. ovum. 18-20. * L. ovum var. conica (Xavier 1989). 21-25. L. ovum var. dimidio-minor. 26-27. L. ovum var. globula. 28. L. oxyuris. 29-30. * L. pyriformis (Xavier 1994). Escala $=10 \mu \mathrm{m}$.

Figures 14-30. Taxa of genus Lepocinclis from the State of São Paulo, SP, Brazil. 14-17. L. ovum var. ovum. 18-20. * L. ovum var. conica (Xavier 1989). 21-25. L. ovum var. dimidio-minor. 26-27. L. ovum var. globula. 28. L. oxyuris. 29-30. * L. pyriformis (Xavier 1994). Scale bar $=10 \mu \mathrm{m}$.

Célula aproximadamente elíptica, 16-23 $\mu \mathrm{m}$ compr., 8-12 $\mu \mathrm{m}$ larg., Rc/1 = 1,3-1,8, pigmentada; polo anterior com proeminência truncada ao redor da abertura do poro flagelar, abertura do canal apical; polo posterior terminando em mamilo curto; película com estrias levogiras; grãos de paramido principais 1-2, anelares, curvados, laterais; cloroplastídios, núcleo e flagelo não observados.
Os indivíduos proporcionalmente mais largos desta variedade assemelham-se àqueles da var. globula (Perty) Lemmermann da mesma espécie, podendo ser distintos pela presença na var. conica Allorge \& Lefèvre de uma proeminência truncada no polo anterior. No Estado de São Paulo, esta variedade foi previamente descrita para os municípios de São Bernardo do Campo (Xavier 1996) e de São Paulo (Xavier 1989, 1994). 
Material examinado: observado apenas na literatura especializada do Estado de São Paulo.

Distribuição geográfica: Norte (Amazonas), Sudeste (Rio de Janeiro e São Paulo).

Lepocinclis ovum (Ehrenberg) Minkevich var. dimidio-minor (Deflandre) Conrad, Mémoires du Musée Royal d'Histoire Naturelle de Belgique 2(1): 42, fig. 33a-h. 1935 三 Lepocinclis ovum f. dimidiominor Deflandre, Bulletin de la Société botanique de France 24(4): 1121, fig. 25-28. 1924.

Figuras 21-25

Célula subcilíndrica a amplamente elíptica, 17-24 $\mu \mathrm{m}$ compr., 7,5-17 $\mu \mathrm{m}$ larg., Rc/1 = 1,3-2,5, pigmentada; polo anterior arredondado, às vezes levemente deprimido, abertura do canal apical; polo posterior terminando em mamilo curto, 1-2,5 $\mu \mathrm{m}$ compr.; película hialina a castanho-amarelada, estrias grossas, levógiras, fácil visualização; cloroplastídios numerosos, discoides, 1,5-3 $\mu \mathrm{m}$ diâm.; grãos de paramido principais 1-2, anelares, curvados, laterais; núcleo aproximadamente esférico, posterior, 4-6 $\mu \mathrm{m}$ diâm.; flagelo emergente 1, 0,75-1 vez o comprimento celular; estigma não observado.

Deflandre (1924) propôs a f. dimidio-minor para incluir espécimes que diferem de L. ovum (Ehrenberg) Minkevich pelas menores dimensões celulares. Conrad (1935) elevou a f. dimidio-minor Deflandre a categoria variedade e ampliou sua circunscrição em relação aos limites de comprimento e largura das células. Também enfatizou que esta variedade difere do tipo da espécie pela forma elíptica mais regular da célula e por suas menores dimensões. Embora não tenha sido detectada sobreposição das medidas do comprimento celular entre L. ovum (Ehrenberg) Minkevich var. dimidio-minor (Deflandre) Conrad e L. ovum (Ehrenberg) Minkevich var. ovum, o intervalo entre os limites métricos de uma e outra variedade foi curto. Além do mais, houve nítida sobreposição das medidas da largura celular e da relação entre o comprimento e a largura da célula, indicando que a identificação com base apenas nas dimensões celulares pode ser problemática. $\mathrm{O}$ uso da morfologia do processo caudal revelou-se, entretanto, eficaz na separação das variedades em pauta, uma vez que a variedade típica o possui relativamente longo e cônico e a var. dimidio-minor (Deflandre) Conrad reduzido e mamilado.

Material examinado: BRASIL. SÃo PAULO: Juquiá, BR116, km 160, alagado, 1-III-1973, C.E.M. Bicudo \& L.
Sormus (SP113672); Rancharia, Vila Agissê, ribeirão Capivari, 25-VIII-1973, D.M. Vital (SP114513); Ibiúna, rodovia Cotia-Ibiúna, km 54, rio Sorocá-Mirim, 19IX-1973, L. Sormus (SP114515); Pontes Gestal, rio Turvo, 23-XI-1973, D.M. Vital (SP114558); Sumaré, Acampamento Batista, lago, 11-II-1975, L. Sormus (SP123865); Pirassununga, SP-225, km 23, bairro Cascalho, lago, ?-XII-1973, P.A.C. Senna (SP123900); Bauru, rio Batalha, próximo da estrada BauruPiratininga, 21-VIII-1973, D.M. Vital (SP130790); Avaré, SP-310, km 276, lago, 23-I-1976, O. Yano \& R.C.A. Souza (SP130956); Porangaba, SP-280, km 127, lago, 11-V-1977, C.R. Leite (SP139741); Pilar do Sul, SP-250, km 127, à direita, sentido São Paulo-Pilar do Sul, bairro Turvinho, rio Turvinho, 17-IV-1989, A.A.J. Castro, C.E.M. Bicudo \& D.C. Bicudo (SP188431); Itanhaém, SP-55, km 332,7, charco com Typha e capim gordura, 12-III-1990, A.A.J. Castro \& C.E.M. Bicudo (SP188434); General Salgado, rodovia Jesulino da Costa Frota (estrada vicinal), 1,5 km da estrada SP-310, local não especificado, com Cyperaceae, gramíneas e Typha, 5-XII-1991, L.H.Z. Branco (SP239241); Capivari, SP-308, km 132, charco com Typha, Eichhornia e Pistia, 20-III-1990, A.A.J. Castro \& C.E.M. Bicudo (SP255723); Moji Guaçu, fazenda Campininha, represa ao lado do açude do Jacaré, com Mayaca, Utricularia e Eichhornia, 12-V-1990, D.C. Bicudo (SP255733); Itaju, SP-304, km 347,5, sentido Ibitinga, açude com plantas aquáticas, 22-II-1992, C.E.M. Bicudo \& D.C. Bicudo (SP255771); Novo Horizonte, SP-304, km 451, charco, 14-II-2001, C.E.M. Bicudo, S.M.M. Faustino \& L.R. Godinho (SP336349); Paraguaçu Paulista, SP-421, km 58, 28-III-2001, C.E.M. Bicudo, L.A. Carneiro \& S.M.M. Faustino (SP336350); Monte Aprazível, estrada vicinal Monte Aprazível-Engenheiro Balduíno, km 0,5, 24-IV-2001, C.E.M. Bicudo, D.L. Costa \& S.M.M. Faustino (SP355374); Jundiaí, SP-360, km 68, riacho, 5-V-2000, C.E.M. Bicudo \& S.P. Schetty (SP365686); Limeira, SP-151, entre km 3 e 4, açude, 5-V-2000, C.E.M. Bicudo \& S.P. Schetty (SP365687).

Distribuição geográfica: Centro-Oeste (Distrito Federal, Goiás e Mato Grosso), Norte (Amazonas), Sudeste (Rio de Janeiro e São Paulo), Sul (Paraná, Rio Grande do Sul e Santa Catarina).

Lepocinclis ovum (Ehrenberg) Minkevich var. globula (Perty) Lemmermann, Berichte der deutsche botanischen Gesellschaft 19: 88. $1901 \equiv$ Lepocinclis globulus Perty, Mittheilungen der Naturforschenden Gesellschaft in Bern 144-166: 28. 1849.

Figuras 26-27 
Célula globosa a subglobosa, 21-23 $\mu \mathrm{m}$ compr., 17-22 $\mu \mathrm{m}$ larg., $\mathrm{Rc} / 1=1,0-1,2$, pigmentada; polos amplamente arredondados; polo posterior terminando em mamilo curto, 1-1,5 $\mu \mathrm{m}$ compr.; película castanhoamarelado claro, estrias grossas, levógiras, fácil visualização; cloroplastídios numerosos, discoides, ca. $3 \mu \mathrm{m}$ diâm.; grãos de paramido principais 1-2, anelares, curvados, laterais; núcleo, estigma e flagelo não observados.

Lepocinclis ovum (Ehrenberg) Minkevich var. globula (Perty) Lemmermann foi proposto como uma combinação nova por Lemmermann (1901) para incluir indivíduos com célula arredondada originalmente descritos como Lepocinclis globulus Perty. A var. globula (Perty) Lemmermann é distinta da típica da espécie por apresentar dimensões celulares menores e processo caudal reduzido, assim como a var. dimidio-minor (Deflandre) Conrad. No entanto, a var. globula (Perty) Lemmermann difere da var. dimidio-minor (Deflandre) Conrad por possuir forma globosa ou subglobosa da célula com menor valor da Rc/1 (1,0-1,2), enquanto que L. ovum (Ehrenberg) Minkevich var. dimidio-minor (Deflandre) Conrad apresenta célula subcilíndrica a amplamente elíptica e maior $\mathrm{Rc} / 1(1,3-2,5)$.

Material examinado: BRASIL, SÃo PAUlo: Andradina, estrada da Lagoinha, Estância Marrequinho, 15-I-1992, L.H.Z. Branco (SP239234); Salesópolis, SP-88, km 99/100, dreno, 18-IX-2001, C.E.M. Bicudo, D.L. Costa \& F.C. Pereira (SP355371).

Distribuição geográfica: Centro-Oeste (Distrito Federal, Goiás e Mato Grosso), Nordeste (Paraíba e Pernambuco), Norte (Amazonas), Sudeste (Rio de Janeiro e São Paulo), Sul (Rio Grande do Sul).

Lepocinclis oxyuris (Schmarda) Marin \& Melkonian in Marinetal., Protist 154: 104.2003 EEuglena oxyuris Schmarda, Kleine Beiträge zur Naturgeschichte der Infusorien. 17, pl. 1, fig. II, 1-7. 1846.

Figura 28

Célula cilíndrica, 131-175 $\mu \mathrm{m}$ compr., 17-34 $\mu \mathrm{m}$ larg., $\mathrm{Rc} / 1=4,1-8,8$, pigmentada, às vezes torcida, elíptica em corte óptico transversal; polo anterior arredondado ou obliquamente truncado, reentrância pronunciada, abertura do canal subapical; polo posterior atenuado em processo caudal hialino, pontiagudo, longo, reto ou ligeiramente inclinado, 19-32 $\mu \mathrm{m}$ compr.; película hialina, estrias finas, dextrógiras, nítidas; cloroplastídios numerosos, discoides, 3-6 $\mu$ m diâm.; grãos de paramido principais
2, elípticos ou bastoniformes com ou sem perfuração central, 1 anterior e outro posterior ao núcleo, 24-37 $\mu \mathrm{m}$ compr., 7-18 $\mu \mathrm{m}$ larg., outros menores elípticos, distribuídos no citoplasma; núcleo arredondado a oblongo, grande, aproximadamente central, 9-20 $\mu \mathrm{m}$ compr., 8-10 $\mu \mathrm{m}$ larg.; flagelo emergente 1, ca. 1/7 do comprimento celular; estigma não observado.

A descrição original de Lepocinclis oxyuris (Schmarda) Marin \& Melkonian in Marin et al. está em Schmarda (1846), como Euglena oxyuris. Diversas variedades e formas taxonômicas foram descritas posteriormente com base nas dimensões celulares das populações examinadas (Kim et al. 1998), por conta da grande amplitude das medidas reportadas por diversos autores (Playfair 1921, Deflandre 1924, Prescott 1944, Gojdics 1953, Huber-Pestalozzi 1955). As dimensões observadas nos espécimes das populações presentemente examinadas foram similares às delimitadas por Bourrelly (1949) para E. oxyuris Schmarda var. charkowiensis (Swirenko) Chu: $125,0-150,0 \times 20,0-27,0 \mu \mathrm{m}$. No entanto, muita controvérsia tem decorrido como consequência do uso de medidas na delimitação de categorias infraespecíficas na espécie. Finalmente, Marin et al. (2003) transferiram E. oxyuris Schmarda para Lepocinclis sob a combinação L. oxyuris (Schmarda) Marin \& Melkonian in Marin et al. Portanto, decidiu-se deixar a presente identificação em nível espécie pelas seguintes razões: (1) as categorias infraespecíficas de $L$. oxyuris (Schmarda) Marin \& Melkonian in Marin et al. ainda não foram trabalhadas em termos moleculares; (2) ainda que se utilize a literatura clássica, a separação de variedades e formas taxonômicas dessa espécie segue bastante contraditória; e (3) Euglena charkowiensis Swirenko, basiônimo de E. oxyuris Schmarda var. charkowiensis (Swirenko) Chu, foi considerada sinônimo taxonômico de Lepocinclis oxyuris (Schmarda) Marin \& Melkonian in Marin et al.

Material examinado: BRASIL. São PAUlo: Guaratinguetá, BR-116, lago próximo do Clube dos 500, 1-IV-1966, C.E.M. Bicudo (SP96956); Andradina, estrada da Lagoinha, Estância Marrequinho, 15-I-1992, L.H.Z. Branco (SP239234); Araçatuba, rodovia Marechal Rondon, local não especificado, com Cyperaceae, gramíneas e Myriophyllum, 15-I-1992, L.H.Z. Branco (SP239239); Reginópolis, SP-331, km 115,2, à esquerda, sentido Pirajuí, lado direito do rio Batalha, $500 \mathrm{~m}$ depois da entrada de Reginópolis, brejo com macrófitas, 22-II-1992, C.E.M. Bicudo \& 
D.C. Bicudo (SP255770); Limeira, SP-151, entre km 3 e 4, açude, 5-V-2000, C.E.M. Bicudo \& S.P. Schetty (SP365687).

Distribuição geográfica: Centro-Oeste (Distrito Federal, Goiás e Mato Grosso), Nordeste (Sergipe), Norte (Amazonas, Rondônia e Tocantins), Sudeste (Rio de Janeiro e São Paulo), Sul (Paraná, Rio Grande do Sul e Santa Catarina).

* Lepocinclis pyriformis Cunha, Memórias do Instituto Oswaldo Cruz 5(2): 109, pl. 10, fig. 1.1913 (como "piriformis", com "i").

Figuras 29-30

Célula obpiriforme, 30-36 $\mu \mathrm{m}$ compr., 16-21,9 $\mu \mathrm{m}$ larg., $\mathrm{Rc} / 1=$ ca. 1,7 , pigmentada; polo anterior arredondado, abertura do canal apical; polo posterior alongado, terminando em processo caudal hialino, cônico, longo, afilado, 8-10 $\mu \mathrm{m}$ compr.; película com estrias dextrógiras; cloroplastídios numerosos, discoides; grãos de paramido principais geralmente 2, anelares, curvados; núcleo excêntrico; flagelo emergente 1, ca. 0,5 do comprimento celular.

Esta espécie apresenta morfologia próxima à de Lepocinclis turbiniformis Deflandre, da qual se distingue pela orientação das estrias, que são levógiras nesta e dextrógiras em L. pyriformis Cunha (Alvesda-Silva \& Hahn 2004). Esta espécie foi previamente descrita para o município de São Paulo por Xavier (1989 e 1994), todavia, não foi reencontrada durante o presente estudo.

Material examinado: observado apenas na literatura especializada do Estado de São Paulo.

Distribuição geográfica: Norte (Amazonas), Sudeste (Rio de Janeiro e São Paulo), Sul (Rio Grande do Sul).

Lepocinclis salina Fritsch var. salina, New Phytologist 13: 352, fig. 3a-b, e. 1914.

Figuras 31-32

Célula ovada a amplamente elíptica, 29-55 $\mu \mathrm{m}$ compr., 22-45 $\mu \mathrm{m}$ larg., Rc/1 = 1,1-1,4, pigmentada; polo anterior assimétrico, abertura do canal subapical, prolongada em depressão lateral, profunda; polo posterior amplamente arredondado; película hialina, estrias dextrógiras, às vezes de difícil visualização; cloroplastídios numerosos, discoides, 2-4 $\mu \mathrm{m}$ diâm.; grãos de paramido numerosos, discoides ou elípticos, nunca anelares, 4-11 $\mu \mathrm{m}$ compr., 3-8 $\mu \mathrm{m}$ larg.; núcleo esférico ou subesférico, ligeiramente posterior, 8-20 $\mu \mathrm{m}$ diâm.; flagelo emergente 1 , ca. 1 vez o comprimento celular; estigma não observado.
Lepocinclis salina Fritsch é uma das espécies melhor conhecidas de Lepocinclis (Conrad 1935). Lembra, morfologicamente, L. texta (Dujardin) Lemmermann. A orientação da torsão das estrias constitui a diferença mais marcante entre essas duas espécies, por ser dextrógira em $L$. salina Fritsch e levógira em $L$. texta (Dujardin) Lemmermann (Alves-da-Silva \& Fortuna 2006). Recentemente, com base molecular, Linton et al. (2010) sugeriram a transferência de L. salina Fritsch para o gênero Phacus, sob a denominação Phacus salina (Fritsch) Linton \& Karnkowska in Linton et al. (epíteto mais tarde corrigido para Phacus salinus). Todavia, Linton et al. (2010) não justificaram a transferência do ponto de vista morfológico, nem avaliaram cepas de L. texta (Dujardin) Lemmermann (espécie morfologicamente mais relacionada com $L$. salina Fritsch). Assim sendo, considerando a falta de base morfológica, bem como o fato de ser ainda pouco adotada esta nova proposição, preferimos por ora manter o basiônimo (Lepocinclis salina Fritsch) para denominar os espécimes do Estado de São Paulo.

Material examinado: BRASIL. São PAULO: Ubatuba, sem indicação precisa do local, 29-I-1966, O. Montes \& R.R. Martins (SP96890); Guaratinguetá, BR-116, lago próximo do Clube dos 500, 1-IV-1966, C.E.M. Bicudo (SP96956); Mogi das Cruzes, SP-88, km 7475, lagoa, 18-VI-1973, C.E.M. Bicudo, C.R. Leite \& L. Sormus (SP113662); Ibiúna, rodovia CotiaIbiúna, km 54, rio Sorocá-Mirim, 19-IX-1973, L. Sormus (SP114515); Sumaré, Acampamento Batista, lago, 11-II-1975, L. Sormus (SP123865); Tupã, sem indicação precisa do local, 20-VII-1973, D.M. Vital (SP130789); Porangaba, SP-280, km 127, lago, 11-V-1977, C.R. Leite (SP139741); Piratininga, rio Água da Faca, 12-V-1977, C.R. Leite (SP139750); Pilar do Sul, SP-250, km 127, à direita, sentido São Paulo-Pilar do Sul, bairro Turvinho, rio Turvinho, 17-IV-1989, A.A.J. Castro, C.E.M. Bicudo \& D.C. Bicudo (SP188431); Brodosqui, rodovia vicinal, km 7, à esquerda, sentido Brodosqui-Jardinópolis, brejo, com Cyperaceae e Typha, 16-XI-1991, A.A.J. Castro (SP255762).

Distribuição geográfica: Centro-Oeste (Distrito Federal, Goiás, Mato Grosso do Sul e Mato Grosso), Norte (Rondônia), Sudeste (Rio de Janeiro e São Paulo), Sul (Rio Grande do Sul).

Lepocinclis salina Fritsch var. vallicauda Conrad, Mémoires du Musée Royal d'Histoire Naturelle de Belgique 2(1): 63. 1935.

Figura 33 


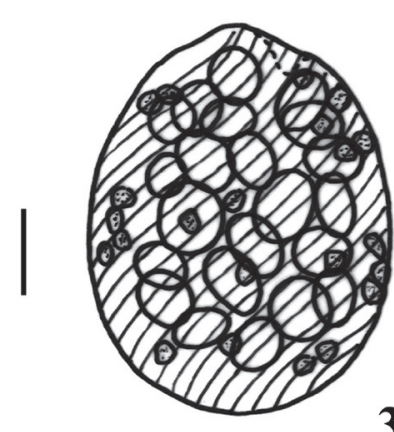

31

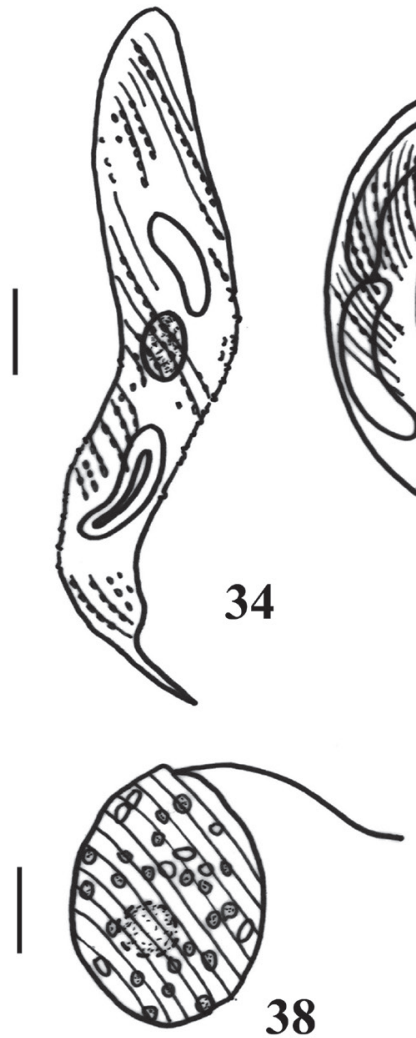

38

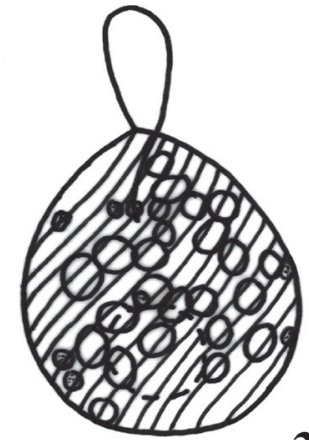

32

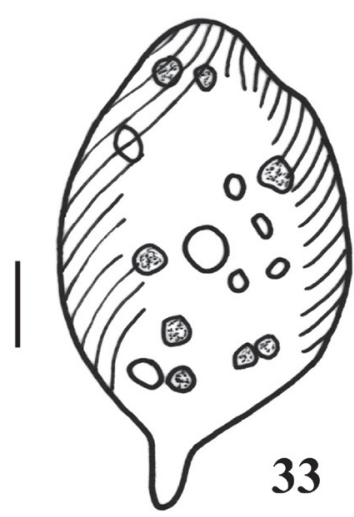

33
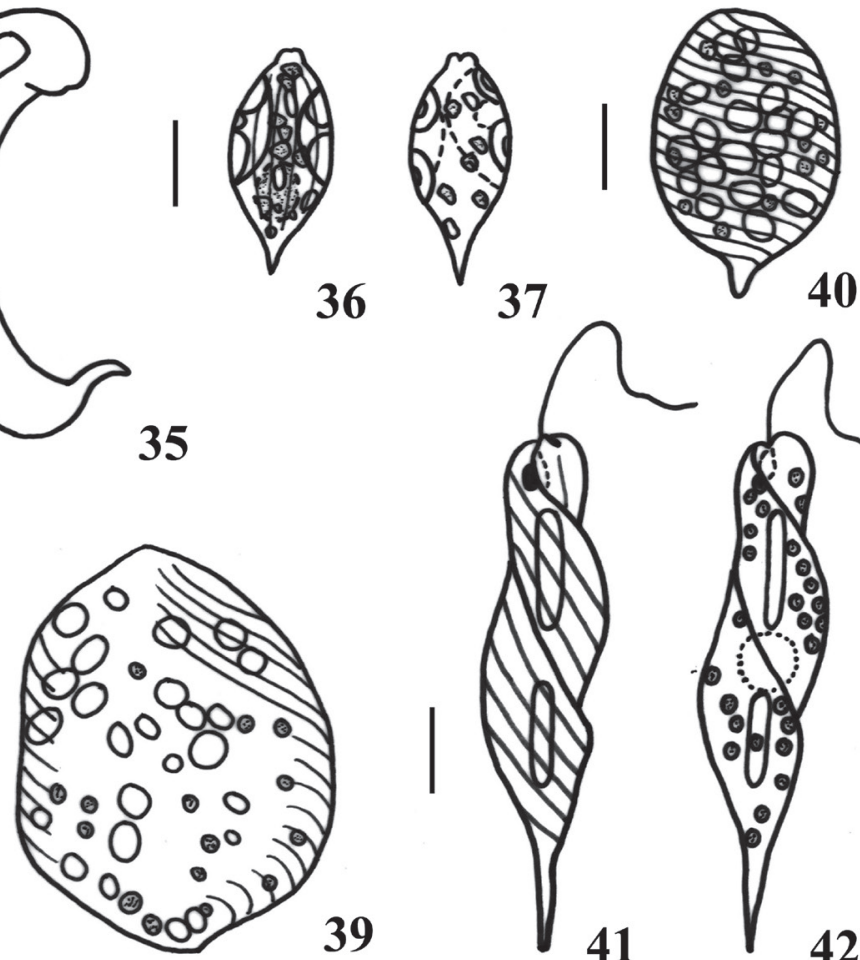

36

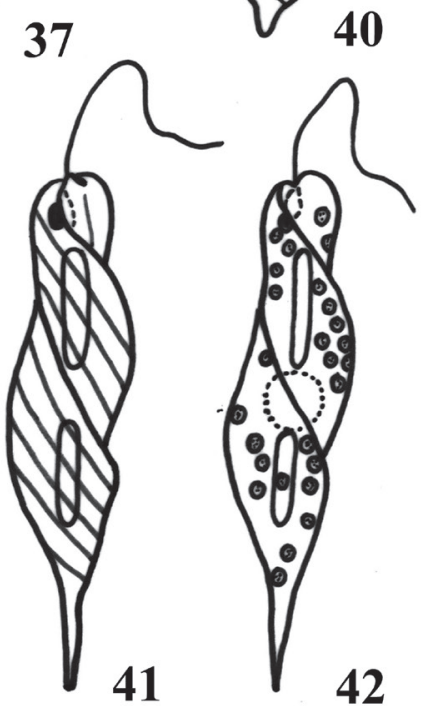

Figuras 31-42. Táxons do gênero Lepocinclis no Estado de São Paulo, SP, Brasil. 31-32. L. salina var. salina. 33. L. salina var. vallicauda. 34-35. L. spirogyroides. 36-37. L. steinii var. steinii. 38-39. L. texta var. texta. 40. L. texta var. richardiana. 41-42. * L. tripteris (Xavier 1994). Escala $=10 \mu \mathrm{m}$.

Figures 31-42. Taxa of genus Lepocinclis from the State of São Paulo, SP, Brazil. 31-32. L. salina var. salina. 33. L. salina var. vallicauda 34-35. L. spirogyroides. 36-37. L. steinii var. steinii. 38-39. L. texta var. texta. 40. L. texta var. richardiana. 41-42. * L. tripteris (Xavier 1994). Scale bar $=10 \mu \mathrm{m}$.

Célula ovada, ca. 60,5 $\mu \mathrm{m}$ compr., ca. $38 \mu \mathrm{m}$ larg., $\mathrm{Rc} / 1=$ ca. 1,6, pigmentada; polo anterior assimétrico, abertura do canal subapical, prolongada em depressão lateral, profunda; polo posterior atenuado em processo caudal cônico-arredondado, ligeiramente inclinado, ca. $8 \mu \mathrm{m}$ compr.; película hialina, estrias dextrogiras; cloroplastídios numerosos, discoides, ca. 4 um diâm.; grãos de paramido numerosos, discoides ou elípticos, nunca anelares, ca. $4 \mu \mathrm{m}$ compr.; núcleo, estigma e flagelo não observados.
Lepocinclis salina Fritsch var. vallicauda Conrad foi proposta por Conrad (1935) para incluir indivíduos que diferem da variedade-tipo da espécie por apresentarem processo caudal cilíndrico, bem desenvolvido. Lepocinclis salina Fritsch var. vallicauda Conrad é morfologicamente semelhante a L. texta (Dujardin) Lemmermann var. richardiana Conrad (Conrad), porém, pode ser diferenciada pela orientação das estrias, que são dextrógiras na var. 
vallicauda Conrad e levógiras na var. richardiana Conrad (Conrad), além desta última var. ser bem menor (ca. $34 \mu \mathrm{m}$ compr., 22-25 $\mu \mathrm{m}$ larg.).

Material examinado: BRASIL, S̃̃o PAULO: Araçatuba, rodovia Marechal Rondon, local não especificado, com Cyperaceae, gramíneas e Myriophyllum, 15-I-1992, L.H.Z. Branco (SP239239).

Distribuição geográfica: Nordeste (Paraíba), Norte (Amazonas), Sudeste (Minas Gerais e São Paulo), Sul (Rio Grande do Sul).

Lepocinclis spirogyroides (Ehrenberg) Marin \& Melkonian in Marin et al., Protist 154: 104. 2003 三 Euglena spirogyra Ehrenberg, Abhandlungen der Königlichen Akademie der Wissenschaften zu Berlin 1830: 83, pl. 6. fig. 4. 1832.

Figuras 34-35

Célula cilíndrica, 70-100 $\mu \mathrm{m}$ compr., 10-15 $\mu \mathrm{m}$ larg., $\mathrm{Rc} / \mathrm{l}=5,4-9,2$, pigmentada, às vezes torcida; polo anterior arredondado, abertura do canal subapical; polo posterior atenuado em processo caudal cônico, longo, curvo, 9-16 $\mu \mathrm{m}$ compr.; película castanhoamarelado claro a castanho-avermelhado escuro, estrias finas, levógiras, cobertas por fileiras de papilas cuboides de tamanho e grau de desenvolvimento variável; cloroplastídios numerosos, discoides, 3-3,5 $\mu \mathrm{m}$ diâm.; grãos de paramido principais 2 , elípticos ou bastoniformes com ou sem perfuração central, 1 anterior, outro posterior ao núcleo, 11-25 $\mu \mathrm{m}$ compr., 2,5-6 $\mu \mathrm{m}$ larg.; núcleo oblongo, grande, aproximadamente central, ca. $8 \mu \mathrm{m}$ compr., ca. 5,7 $\mu \mathrm{m}$ larg.; estigma e flagelo não observados.

A descrição original desta espécie está em Ehrenberg (1838), que a denominou Euglena spirogyra Ehrenberg. Posteriormente, Klebs (1883) propôs a var. fusca e Lemmermann (1910) elevou esta variedade à categoria espécie, fato que deu início a muitas divergências taxonômicas (Xavier 1988). Recentemente, Marin et al. (2003) transferiram E. spirogyra Ehrenberg para o gênero Lepocinclis, sob a combinação L. spirogyroides (Ehrenberg) Marin \& Melkonian in Marin et al. Kosmala et al. (2005) confirmaram com dados moleculares e morfológicos que se trata de dois táxons distintos, resolvendo o problema ao propor uma nova combinação, $L$. fusca (Klebs) Kosmala \& Zakryś in Kosmala et al. De acordo com os últimos autores, as únicas características diagnósticas confiáveis para separar L. spirogyroides (Ehrenberg) Marin \& Melkonian in Marin et al. de L. fusca (Klebs) Kosmala \& Zakryś in Kosmala et al. são a forma e o tamanho das células e a forma das papilas. Lepocinclis spirogyroides (Ehrenberg) Marin \& Melkonian in Marin et al. pode ser facilmente reconhecido pela presença de papilas cubóides sobre as estrias, no que difere de L. fusca (Klebs) Kosmala \& Zakryś in Kosmala et al. que apresenta papilas piramidais ou piramidal truncadas.

Material examinado: BRASIL. São PAUlo: Bauru, rio Batalha, próximo da estrada Bauru-Piratininga, 21-VIII-1973, D.M. Vital (SP130790); Avaí, Estância Aruanã, lago, 12-V-1977, C.R. Leite (SP139747); Andradina, estrada da Lagoinha, Estância Marrequinho, 15-I-1992, L.H.Z. Branco (SP239234); Mirassol, SP-310, km 410,7, charco com gramíneas, fundo argiloso, 10-IV-1990, A.A.J. Castro \& C.E.M. Bicudo (SP255728); Novo Horizonte, SP-304, km 451, charco, 14-II-2001, C.E.M. Bicudo, S.M.M. Faustino \& L.R. Godinho (SP336349); Jundiaí, SP360, km 68, riacho, 05-V-2000, C.E.M. Bicudo \& S.P. Schetty (SP365686).

Distribuição geográfica: Centro-Oeste (Distrito Federal, Goiás e Mato Grosso), Nordeste (Sergipe), Norte (Acre, Amazonas e Tocantins), Sudeste (Rio de Janeiro e São Paulo), Sul (Rio Grande do Sul e Santa Catarina).

Lepocinclis steinii Lemmermann emend. Conrad var. steinii, Archiv für Protistenkunde 82(2): 206207, fig. 4-5. 1934 ELepocinclis ovum var. steinii Lemmermann, Berichte der deutsche botanischen Gesellschaft 19: 89. 1901.

Figuras 36-37

Célula fusiforme, 27-28 $\mu \mathrm{m}$ compr., 12-13,5 $\mu \mathrm{m}$ larg., $\mathrm{Rc} / 1=2,0-2,3$, pigmentada; polo anterior com proeminência truncada ao redor da abertura do poro flagelar, abertura do canal apical; polo posterior estendido em processo caudal hialino, cônico, 4,5-5 $\mu \mathrm{m}$ compr.; película hialina a castanho-amarelado claro, estrias longitudinais delicadas, difícil visualização; cloroplastídios numerosos, discoides, 2-3 $\mu$ m diâm.; grãos de paramido principais 2, anelares, laterais, curvados; núcleo oblongo, posterior, ca. $8 \mu \mathrm{m}$ compr., ca. $6 \mu \mathrm{m}$ larg.; estigma e flagelo não observados.

Lepocinclis steinii Lemmermann emend. Conrad lembra morfologicamente L. ovum (Ehrenberg) Minkevich var. dimidio-minor (Deflandre) Conrad, da qual é diferente pela orientação longitudinal das estrias, pelo polo anterior proporcionalmente mais desenvolvido e pelas maiores dimensões celulares (Alves-da-Silva \& Hahn 2004). Em 
literatura, é geralmente mencionada a presença de estrias longitudinais nítidas. Contudo, os espécimes analisados durante o presente estudo apresentaram estrias longitudinais tênues concordantes com a descrição de muitos exemplares observados por Alves-da-Silva \& Torres (1992) em populações do Rio Grande do Sul.

Material examinado: BRASIL. São PAULo: Itaí, SP255, km 308,3, Represa de Jurumirim, lado direito, sentido Itaí-Taquarituba, presença de Myriophyllum e Eichhornia, 10-IX-1991, A.A.J. Castro, C.E.M. Bicudo \& M.R. Marques-Lopes (SP255760); Salesópolis, SP88, km 99/100, dreno, 18-IX-2001, C.E.M. Bicudo, D.L. Costa \& F.C. Pereira (SP355371).

Distribuição geográfica: Sudeste (Rio de Janeiro e São Paulo), Sul (Rio Grande do Sul).

Lepocinclis texta (Dujardin) Lemmermann var. texta, Berichte derdeutschebotanischen Gesellschaft 19:90. 1901 ECrumenula texta Dujardin, Histoire naturelle des Zoophytes: 339, pl. 5, fig. 8. 1841.

Figuras 38-39

Célula ovada a amplamente ovada, 29-54 $\mu \mathrm{m}$ compr., 22-41 $\mu \mathrm{m}$ larg., Rc/1 = 1,1-1,6, pigmentada; polo anterior assimétrico, abertura do canal subapical, 1 reentrância; polo posterior amplamente arredondado; película hialina, estrias levógiras, às vezes de difícil visualização; cloroplastídios numerosos, discoides, 1,5-4 $\mu \mathrm{m}$ diâm.; grãos de paramido numerosos, discoides ou elípticos, 3-8 $\mu \mathrm{m}$ compr., 2-6 $\mu \mathrm{m}$ larg.; núcleo esférico ou subesférico, central ou ligeiramente posterior, 6-13 $\mu \mathrm{m}$ diâm.; flagelo emergente 1, ca. 1 vez o comprimento celular; estigma não observado.

Os espécimes-tipo de Lepocinclis salina Fritsch e L. texta (Dujardin) Lemmermann são morfologicamente muito semelhantes entre si e podem ser confundidos. Contudo, as duas espécies podem ser diferenciadas pelo sentido dextrógiro de estriação da película em $L$. salina Fritsch e levógiro em $L$. texta (Dujardin) Lemmermann e pela depressão no polo anterior muito mais pronunciada em L. salina Fritsch (Xavier 1989).

Material examinado: BRASIL, São Paulo: Avaré, SP-310, km 276, lago, 23-I-1976, O. Yano \& R.C.A. Souza (SP130956); Novo Horizonte, SP-304, km 451, charco, 14-II-2001, C.E.M. Bicudo, S.M.M. Faustino \& L.R. Godinho (SP336349); Paraguaçu Paulista, SP-421, km 58, 28-III-2001, C.E.M. Bicudo, L.A. Carneiro \& S.M.M. Faustino (SP336350);
Piquete, estrada Lorena-Piquete, $\mathrm{km} \mathrm{65}$, riacho, 19-IX-2001, C.E.M. Bicudo, D.L. Costa \& F.C. Pereira (SP355360); Santo Antônio de Aracanguá, SP-320, km 463, lago, 25-IV-2001, C.E.M. Bicudo, D.L. Costa \& S.M.M. Faustino (SP355386); Zacarias, rio Tietê, 14-VIII-2001, C.E.M. Bicudo, D. Santos \& L. Godinho (SP370969).

Distribuição geográfica: Nordeste (Bahia), Norte (Amazonas), Sudeste (Rio de Janeiro e São Paulo), Sul (Rio Grande do Sul).

Lepocinclis texta (Dujardin) Lemmermann var. richardiana Conrad (Conrad), Mémoires du Musée Royal d'Histoire Naturelle de Belgique 2(1): 24, fig. 13. 1935 =Lepocinclis ovum (Ehrenberg) Minkevich var. richardiana Conrad, Archiv für Protistenkunde 82(2): 218, fig. 17. 1934.

Figuras 40

Célula ovada, ca. $34 \mu \mathrm{m}$ compr., 22-25 $\mu \mathrm{m}$ larg., $\mathrm{Rc} / 1=1,4-1,6$, pigmentada; polo anterior assimétrico, abertura do canal subapical, reentrância discreta; polo posterior atenuado em processo caudal cônico-arredondado, ligeiramente inclinado, 3-4 $\mu \mathrm{m}$ compr.; película hialina, estrias levógiras, nítidas; cloroplastídios numerosos, discoides, ca. 2,5 $\mu \mathrm{m}$ diâm.; grãos de paramido numerosos, discoides ou elípticos, 4-5 $\mu \mathrm{m}$ compr., 2,4-4 $\mu \mathrm{m}$ larg.; núcleo, estigma e flagelo não observados.

A var. richardiana Conrad (Conrad) difere da típica da espécie pela forma mais alongada da célula, pela menor reentrância no polo anterior e, principalmente, pela presença de processo caudal relativamente longo (Xavier 1989). De acordo com Conrad (1935), L. texta (Dujardin) Lemmermann var. richardiana Conrad (Conrad) apresenta morfologia próxima à de L. salina Fritsch var. vallicauda Conrad., mas difere pela orientação das estrias, que são levógiras na var. richardiana Conrad (Conrad) e dextrógiras na var. vallicauda Conrad.

Material examinado: BRASIL. São PAULO: Salesópolis, SP-88, km 99/100, dreno, 18-IX-2001, C.E.M. Bicudo, D.L. Costa \& F.C. Pereira (SP355371).

Distribuição geográfica: Sudeste (São Paulo).

* Lepocinclis tripteris (Dujardin) Marin \& Melkonian in Marin et al., Protist 154:104. 2003 三 Phacus tripteris Dujardin, Histoire Naturelle des Zoophytes: 338, pl. 5, fig. 7. 1841.

Figuras 41-42 
Célula fusiforme alongada, 63-73(-102,8) $\mu \mathrm{m}$ compr., 12-16 $\mu \mathrm{m}$ larg., $\mathrm{Rc} / 1=4,5-5,4(-8,0)$, pigmentada, torcida, triangular em corte óptico transversal; polo anterior arredondado, abertura do canal subapical; polo posterior atenuado em processo caudal hialino, cônico, longo; película com estrias finas, longitudinais, seguindo a torção celular; cloroplastídios numerosos, discoides, 4-4,5 $\mu \mathrm{m}$ diâm.; grãos de paramido principais 2, bastoniformes, 1 anterior e outro posterior ao núcleo, 13-17 $\mu \mathrm{m}$ compr., 2-4 $\mu \mathrm{m}$ larg.; núcleo arredondado ou elíptico, grande, aproximadamente central; estigma lateral, vermelhovivo; flagelo emergente $1,0,5-0,75$ do comprimento celular.

A descrição original da espécie é apresentada em Dujardin (1841), que a denominou Phacus tripteris. Klebs (1883) transferiu Phacus tripteris Dujardin para o gênero Euglena, como E. tripteris (Dujardin) Klebs. Esta combinação foi amplamente utilizada na literatura mundial até recentemente, quando Marin et al. (2003) transferiram Euglena tripteris (Dujardin) Klebs para o gênero Lepocinclis. A revisão taxonômica apresentada por Marin et al. (2003) também incluiu o estabelecimento de diversos sinônimos heterotípicos para Lepocinclis tripteris (Dujardin) Marin \& Melkonian in Marin et al., entre eles Euglena torta Stokes, Euglena pseudospiroides Swirenko, Euglena fronsundulata Johnson e Euglena trisulcata Johnson. Todos os representantes das cinco espécies são caracterizados por apresentarem corte óptico transversal triangular, feição esta considerada a diagnóstica principal para identificação taxonômica. No Estado de São Paulo, esta espécie foi previamente descrita para os municípios de São José dos Campos (Cardoso 1979) e de São Paulo (Xavier 1988 e 1994).

Material examinado: observado apenas na literatura especializada do Estado de São Paulo.

Distribuição geográfica: Norte (Amazonas), Sudeste (Rio de Janeiro e São Paulo), Sul (Paraná e Rio Grande do Sul). Primeira vez a ser mencionada para o Brasil como Lepocinclis tripteris (Dujardin) Marin \& Melkonian in Marin et al.

Observou-se a presença de espécimes do gênero Lepocinclis em 46 (43\%) das 107 unidades amostrais avaliadas e em 14 trabalhos da literatura especializada do Estado de São Paulo com possibilidade de reidentificação.

O município com maior número de táxons registrados nas unidades amostrais examinadas foi
Andradina, com seis táxons, seguido pelos municípios de Porangaba e Novo Horizonte, com cinco táxons cada. Os táxons mais amplamente distribuídos na área do Estado de São Paulo foram: Lepocinclis ovum (Ehrenberg) Minkevich var. dimidio-minor (Deflandre) Conrad (20 municípios), Lepocinclis acus (O.F. Müller) Marin \& Melkonian in Marin et al. var. acus (14 municípios) e Lepocinclis fusca (Klebs) Kosmala \& Zakryś in Kosmala et al. (12 municípios).

Foram encontrados 14 táxons de Lepocinclis tanto nas unidades amostrais examinadas como na literatura especializada e quatro foram exclusivos da literatura, ou seja, não foram reencontrados durante esta pesquisa, conforme segue: Lepocinclis cylindrica (Koršikov) Conrad var. cylindrica, Lepocinclis ovum (Ehrenberg) Minkevich var. conica Allorge \& Lefèvre, Lepocinclis pyriformis Cunha e Lepocinclis tripteris (Dujardin) Marin \& Melkonian.

A literatura especializada documentou, até o momento, a ocorrência do gênero Lepocinclis apenas em seis municípios do Estado. Com o presente levantamento florístico, 50 municípios passaram a ter descrição e ilustração de representantes do gênero. Portanto, houve um aumento expressivo no número de municípios em que ocorrem comprovadamente representantes de Lepocinclis, da ordem de mais de oito vezes.

Entre os seis municípios, São Paulo apresentou maior quantidade de táxons nos trabalhos consultados, totalizando 18 táxons específicos e infra-específicos descritos em nove trabalhos taxonômicos. O município de São Bernardo do Campo foi representado por três táxons, os municípios de Ribeirão Preto e São José dos Campos por dois e os municípios de Juquiá e Mogi Guaçu por apenas um táxon. Salienta-se que cada um destes cinco municípios apresentou espécimes de Lepocinclis em apenas um trabalho da literatura do Estado de São Paulo.

O presente levantamento também permitiu ampliar o conhecimento sobre a distribuição geográfica local e regional do gênero Lepocinclis. Neste sentido, Lepocinclis acus (O.F. Müller) Marin \& Melkonian in Marin et al. var. longissima (Deflandre) D.A. Kapustin constituiu primeira citação de ocorrência no Estado de São Paulo e Lepocinclis fusiformis (Carter) Lemmermann var. amphirhynchus Nygaard na região Sudeste do Brasil.

Outra importante contribuição deste estudo foi a atualização da nomenclatura das Euglenophyceae do Estado de São Paulo. Entre os 18 táxons presentes na literatura especializada, cinco foram descritos 
como pertencentes ao gênero Euglena Ehrenberg e um como Cyclidiopsis Koršikov e recentemente transferidos para Lepocinclis por Marin et al. (2003) e Bennett \& Triemer (2014), respectivamente. Deste modo, até o momento estavam formalmente descritos para o Estado de São Paulo como integrantes do gênero Lepocinclis apenas 12 táxons específicos ou infraespecíficos.

As espécies em que foi constatada a maior ocorrência de polimorfismo foram Lepocinclis acus (O.F. Müller) Marin \& Melkonian, L. ovum (Ehrenberg) Minkevich e Lepocinclis salina Fritsch, as quais apresentam uma protusão de variedades e formas taxonômicas na literatura clássica das Euglenophyceae. Embora estes táxons estejam representados em vários trabalhos baseados em biologia molecular, ainda carecem de estudos de revisão que possam definir os reais limites da circunscrição das espécies e principalmente de suas categorias infraespecíficas, bem como possíveis sinônimos taxonômicos. Portanto, é fundamental que se processe a identificação sempre em nível populacional, dada a acentuada plasticidade fenotípica de muitos táxons do gênero Lepocinclis.

\section{Agradecimentos}

À Fundação de Amparo à Pesquisa do Estado de São Paulo - FAPESP, pela concessão de bolsa de doutorado (Processo 2012/06683-0).

\section{Literatura citada}

Alves-da-Silva, S.M. \& Bicudo, C.E.M. 2009. Cryptoglena, Monomorphina and Phacus (Euglenophyceae) of a reservoir in the State of Rio Grande do Sul, southern Brazil. Revista Brasileira de Botânica 32: 253-270.

Alves-da-Silva, S.M. \& Bridi, F.C. 2004. Estudo de Euglenophyta no Parque Estadual Delta do Jacuí, Rio Grande do Sul, Brasil. 2. Os gêneros Phacus Dujardin e Hyalophacus (Pringshein) Pochmann. Iheringia, Série Botânica, 59: 75-96.

Alves-da-Silva, S.M. \& Fortuna, J.R. 2006. Euglenophyceae de ambientes lênticos na planície costeira do Rio Grande do Sul, sul do Brasil: gêneros Euglena Ehr. e Lepocinclis Perty. Acta Botanica Brasilica 20: 411-422.

Alves-da-Silva, S.M \& Hahn, A.T. 2004. Study of Euglenophyta in the Jucuí Delta State Park, Rio Grande do Sul, Brazil. 1. Euglena Ehr., Lepocinclis Perty. Acta Botanica Brasilica 18: 123-140.

Alves-da-Silva, S.M. \& Menezes, M. 2015. Euglenophyceae in Lista de Espécies da Flora do Brasil. Jardim Botânico do Rio de Janeiro.
Alves-da-Silva, S.M \& Torres, J.R. 1992. Estudo taxonômico do gênero Lepocinclis Perty (Euglenaceae), no Parque Zoológico de Sapucaia do Sul e no Jardim Botânico de Porto Alegre, Rio Grande do Sul, Brasil. Iheringia, Série Botânica, 42: 87-104.

Alves-da-Silva, S.M \& Torres, J.R. 1994. O gênero Euglena Ehr. de sistemas lênticos do Parque Zoológico e Jardim Botânico, Rio Grande do Sul, Brasil. Revista Brasileira de Biologia 54: 345-363.

Alves-da-Silva, S.M., Escobar, K.C. \& Juliano, V.B. 2016. Novos registros de Trachelomonas Ehr. emend. Defl. (Euglenophyceae) para o Estado do Rio Grande do Sul e Brasil. Hoehnea 43: 1-10.

Alves-da-Silva, S.M., Cabreira, J.C., Consoni, K.F. \& Lobo, E.A. 2013. Gênero Strombomonas Deflandre (Euglenophyceae pigmentadas) em ambiente lótico subtropical, município de Triunfo, RS, Brasil: riqueza e distribuição. Hoehnea 40: 381-402.

Alves-da-Silva, S.M., Bicudo, C.E.M., Consoni, K.F., Silva, L.S. \& Borges, C.L.L. 2011. Genus Lepocinclis (Euglenophyceae) along five years in the área of influence of the Southern Petrochemical Pole, Rio Grande do Sul State, Brazil. Hoehnea 38: 257-272.

Araujo, G.J.M., Barbosa, J.E.L. \& Barbosa, L.G. 2012. Pigmented Euglenophytes in a natural and shallow lake in the semiarid region of Paraíba State, Brazil. Brazilian Journal of Botany 35: 17-30.

Bennett, M.S. \& Triemer, R.E. 2012. A new method for obtaining nuclear genes sequences from field samples and taxonomic revisions of the photosynthetic euglenoids Lepocinclis [Euglena] helicoideus and Lepocinclis [Phacus] horridus (Euglenophyta). Journal of Phycology 48: 254-260.

Bennett, M.S. \& Triemer, R.E. 2014. The Genus Cyclidiopsis: An Obituary. Journal of Eukaryotic Microbiology 61: 166-172.

Bicudo, C.E.M. 2010. Criptógamos do Parque Estadual das Fontes do Ipiranga, São Paulo, SP. Algas, 28: Euglenophyceae (família Eutreptiaceae). Hoehnea 37: 377-381.

Bicudo, C.E.M. \& Bicudo, R.M.T. 1970. Algas de águas continentais brasileiras. FUNBEC, São Paulo.

Bicudo, C.E.M. \& Menezes, M. 2006. Gêneros de algas de águas continentais do Brasil: chave para identificação e descrições. 2 ed. RiMa Editora, São Carlos.

Bourrelly, P. 1949. Euglena oxyuris Schmarda et formes affines. Bulletin du Muséum National d'Histoire Naturelle, Série 2, 21: 612-16.

Bourrelly, P. 1970. Les algues d'eau douce: iniciation à la systématique: les algues vertes. v. 1. Éditions N. Boubée $\&$ Cie, Paris.

Brosnan, S., Shin, W., Kjer, L.M. \& Trimer, R.E. 2003. Phylogeny of the photosynthetic Euglenophytes inferred from the nuclear SSU and partial LSU rDNA. International Journal of Systematic and Evolutionary Microbiology 53: 1175-1186. 
Busse, I. \& Preisfeld, A. 2002. Phylogenetic position of Rhynchopus sp. and Diplonema ambulator as indicated by analyses of euglenozoan small subunit ribosomal DNA. Gene 284: 83-91.

Busse, I. \& Preisfeld, A. 2003. Systematic of primary osmotrophic euglenids: a molecular approach to the phylogeny of Distigma and Astasia (Euglenozoa). International Journal of Systematic and Evolutionary Microbiology 53: 617-624.

Busse, I., Patterson, D.J. \& Preisfeld, A. 2003. Phylogeny of phagotrophic euglenids (Euglenozoa): a molecular approach based on culture material and environmental samples. Journal of Phycology 39: 828-836.

Cardoso, M.B. 1979. Ficoflórula da lagoa de estabilização de São José dos Campos, Estado de São Paulo, Brasil, exclusive Bacillariophyceae. Dissertação de Mestrado, Universidade de São Paulo, São Paulo.

Conforti, V. 1994. Study of the Euglenophyta from Camaleão Lake (Manaus, Brazil). III. Euglena Ehr., Lepocinclis Perty, Phacus Duj. Revue Hydrobiologique Tropicale 27: 3-21.

Conrad, W. 1934. Matériaux por une monographie du genre Lepocinclis Perty. Archiv fur Protistenkunde 82: 14-249.

Conrad, W. 1935. Étude systématique du genre Lepocinclis Perty. Musée Royal Naturelle de Belgique 1: 1-85.

Deflandre, G. 1924. Additions à la flore algologique des environs de Paris. Ill Flagellées. Bulletin de la Société Botanique de France 71: 1115-1129.

Dujardin, F. 1841. Histoire Naturelle des Zoophytes Infusoires. Roret, Paris.

Ehrenberg, C.G. 1838. Die Infusionsthierchen als voelkommene Organismen: ein Blick in das Tiefere organische Leben der Natur. Verlag von Leopold Voss, Leipizig.

Gojdics, M. 1953. The genus Euglena. The University of Wisconsin Press, Madison.

Huber-Pestalozzi, G. 1955. Euglenophyceen. In: G. HuberPestalozzi (ed.). Das Phytoplakton des Susswasser, Systematik end Biologie. Teil 4, E. Schweizerbart'sche Verlangsbuchhandlung, Stuttgart, pp. 1-605.

Kapustin, D.A. 2011. New nomenclature and taxonomical combinations within euglenophytes. Algologia 21: 137-144.

Kim, J.I., Shin, W. \& Triemer, R.E. 2010. Multigene analyses of photosynthetic euglenoids and new family, Phacaceae (Euglenales). Journal of Phycology 46: 1278-1287.

Kim, J.T., Boo, S.M. \& Zakryś, B. 1998. Floristic and Taxonomic Accounts of the Genus Euglena (Euglenophyceae) from Korean fresh water. Algae 13: 173-197.

Klebs, G. 1883. Über die Organization einiger Flagellatengruppen und ihre Beziehungen zu Algen und Infusorien. Untersuchungen aus dem botanischen Institut zu Tübingen 1: 233-362.
Koršikov, A.A. 1928. Notes on some new flagellates. Archives Russes de Protistologie Moscow 7: 151-158.

Kosmala, S., Karnkowska, A., Milanowski, R., Kwiatowski, J. \& Zakrýs, B. 2005. The Phylogenetic and taxonomic position of Lepocinclis fusca comb. nov. (=Euglena fusca) (Euglenaceae): morphological and molecular justification. Journal of Phycology 41: 1258-1267.

Leander, B.S. \& Farmer, M.A. 2001. Evolution of Phacus (Euglenophyceae) as inferred from pellicle morphology and SSU r DNA. Journal of Phycology 37: 143-159.

Leander, B.S., Triemer, R.E. \& Farmer, M.A. 2001. Character evolution in heterotrophic euglenids. European Journal of Protistology 37: 337-356.

Lemmermann, E. 1901. Beiträge zur Kenntniss der Planktonalgen. XII. Notizen über einige Schwebealgen. XIII. Das Phytoplankton des Ryck und des Greifswalder Boddens. Berichte der deutsche botanischen Gesellschaft 19: 85-95.

Lemmermann, E. 1910. Algen I (Schizophyceen, Flagellaten, Peridineen). In: Kryptogamenflora der Mark Brandenburg und angrenzender Gebiete herausgegeben von dem Botanishcen Verein der Provinz Brandenburg. Dritter Band. Leipzig: Verlag von Grebrüder Borntraeger. pp. 497-712.

Linton, E.W., Karnkowska-Ishikawa, A., Kim, J.I., Shin, W., Bennett, M.S., Kwiatowski, J., Zakryś, B. \& Triemer, R.E. 2010. Reconstructing Euglenoid evolutionary relationships using three genes: nuclear SSU and LSU and chloroplast SSU rDNA sequences and the description of Euglenaria gen. nov. (Euglenophyta). Protist 161: 603-619.

Linton, E.W., Nudelman, M.A., Conforti, V. \& Triemer, R.E. 2000. A molecular analysis af the euglenophytes using rDNA. Journal of Phycology 36: 740-746.

Linton, E.W., Hittner, D., Lewandowski, C., Auld, T. \& Triemer, R.E. 1999. A molecular study of euglenoid phylogeny using small subunit rDNA. Journal of Eukaryotic Microbiology 46: 217-223.

Marin, B., Palm, A., Klingber, M. \& Melkonian, M. 2003. Phylogeny and Taxonomic Revision of PlastidContaining Euglenophytes based on SSU rDNA Sequence Comparions and Synapomorphic Signatures in the SSU rRNA Secondary Structure. Protist 154: 99-145.

Menezes, M. 1987. Polimorfismo em Lepocinclis ovum (Ehr.) Lemm. e suas implicações taxonômicas. Rickia 14: 1-6.

Menezes, M. 1989. Contribuição ao conhecimento das algas do gênero Euglena (Euglenophyceae) no município do Rio de Janeiro e arredores, Brasil. Acta Botanica Brasilica 3: 49-90.

Menezes, M. 1994. Fitoflagelados de quatro corpos d'água da região sul do município do Rio de Janeiro, Estado do Rio de Janeiro, Brasil. Tese de Doutorado, Universidade de São Paulo, São Paulo. 
Menezes, M. \& Fernandes, V.O. 1989. Euglenaceae (Euglenophyceae) pigmentadas do noroeste do Estado do Mato Grosso, Brasil: municípios de Barra dos Bugres, Cáceres, Juína e Porto Esperidião. Hoehnea 16: 35-55.

Milanowski, R., Zakrys, B. \& Kwiatowski, J. 2001. Phylogenetic analysis of chloroplast small-subunit rDNA genes of the genus Euglena Ehrenberg. International Journal of Systematic and Evolutionary Microbiology 51: 773-781.

Müllner, A.N., Angeler, D.G., Samuel, R., Linton, E.W. \& Triemer, R.E. 2001. Phylogenetic analysis of phagotrophic, phototrophic and osmotrophic euglenoids by using the nuclear 18S rDNA sequence. International Journal of Systematic and Evolutionary Microbiology 51: 783-791.

Németh, J. 1980. Az ostoros Algák (Euglenophyta). Série Hidrobiológia 8. Kishatározóija Vizdock, Budapeste.

Nudelman, M.A., Rossi, M.S., Conforti, V. \& Triemer, R.E. 2003. Phylogeny of Euglenophyceae based on small subunit $r$ DNA sequences: taxonomic implications. Journal of Phycology 39: 226-235.

Playfair, G.I. 1921. Australian Freshwater Flagellates. Proceedings of the Linnean Society of New South Wales 46: 99-146.

Preisfeld, A., Berger, S., Busse, I., Liller, S. \& Ruppel, H.G. 2000. Phylogenetic analyses of various euglenoid taxa (Euglenozoa) based on 18 rDNA sequence data. Journal of Phycology 36: 220-226.

Preisfeld, A., Busse, I., Klingberg, M., Talke, S. \& Ruppel, H.G. 2001. Phylogenetic position and inter-relationships of the osmotrophic euglenoids based on SSU rDNA data, with emphasis on the Rhabdomonadales (Euglenozoa). International Journal of Systematic and Evolutionary 51: 751-758.
Prescott, G.W. 1944. New species and varieties of Wisconsin algae. Farlowia 1: 347-385.

Schmarda, L.K. 1846. Kleine Beitrage zur Naturgeschichte der Infusorien. Verlag der Carl Haas' schen Buchhandeung, Wien.

Skvortzov, B.V. \& Noda, M. 1969. On species of genus Cyclidiopsis Korsch. (Euglenaaceae) from South America. Science Reports of Niigata University, series D, 6: 93-95.

Tell, G. \& Conforti, V. 1986. Euglenophyta Pigmentadas de la Argentina. Bibliotheca Phicologica 75: 1-301.

Triemer, R.E. \& Farmer, M.A. 2007. A decade of euglenoid molecular phylogenetics. In: J. Brodie \& J. Lewis (eds.). Unravelling the algae: the past, present, and future of algal systematics. CRC Press, Boca Raton, pp. 315-330.

Van Oye, P. 1924. Note sur l'Euglena acus Ehrbg. Bulletin de la Societé Royal Botanique de Belgique 56: 1-9.

Xavier, M.B. 1988. O gênero Euglena Ehrenberg de lagos do Parque Estadual das Fontes do Ipiranga, São Paulo, Brasil. Hoehnea 15: 65-87.

Xavier, M.B. 1989. O gênero Lepocinclis Perty de lagos do Parque Estadual das Fontes do Ipiranga, São Paulo, Brasil. Hoehnea 16: 133-147.

Xavier, M.B. 1994. Criptógamos do Parque Estadual das Fontes do Ipiranga, São Paulo, SP. Algas, 5: Euglenophyceae (Euglenophyceae Pigmentadas). Hoehnea 21: 47-73.

Xavier, M.B. 1996. Fitoplâncton do Rio Grande, Represa Billings, São Paulo, Brasil: Estudo Taxonômico (19851986). Iheringia, Série Botânica 47: 103-122. 